\title{
Methylated circulating tumor DNA as a biomarker for colorectal cancer diagnosis, prognosis, and prediction
}

\author{
Farah J. Nassar ${ }^{1}$, Zahraa S. Msheik², Rihab R. Nasr ${ }^{2 *}$ (I) and Sally N. Temraz ${ }^{1^{*}}$
}

\begin{abstract}
Worldwide, colorectal cancer (CRC) is a deadly disease whose death rate ranks second among cancers though its incidence ranks third. Early CRC detection is key and is associated with improved survival outcomes. However, existing tests for CRC diagnosis have several weaknesses thus rendering them inefficient. Moreover, reliable prognostic tests that can predict the overall cancer outcome and recurrence of the disease as well as predictive markers that can assess effectiveness of therapy are still lacking. Thus, shifting to noninvasive liquid biopsy or blood-based biomarkers is vital to improving CRC diagnosis, prognosis, and prediction. Methylated circulating tumor DNA (ctDNA) has gained increased attention as a type of liquid biopsy that is tumor-derived fragmented DNA with epigenetic alterations. Methylated ctDNA are more consistently present in blood of cancer patients as compared to mutated ctDNA. Hence, methylated ctDNA serves as a potential biomarker for CRC that is worth investigating. In this review, we explore what has been reported about methylated ctDNA as a biomarker for CRC diagnosis that can distinguish between CRC patients or those having adenoma and healthy controls as validated specifically through ROC curves. We also examine methylated ctDNA as a biomarker for CRC prognosis and prediction as confirmed through robust statistical analyses. Finally, we discuss the major technical challenges that limits the use of methylated ctDNA for clinical application and suggest possible recommendations to enhance its usage.
\end{abstract}

Keywords: Methylation, Colorectal cancer, Circulating biomarker, Diagnosis, Prognosis and prediction

\section{Introduction}

Colorectal cancer $(\mathrm{CRC})$ is considered the third most commonly diagnosed (10.2\%) and the second most fatal (9.2\%) cancer worldwide among both sexes combined [1]. In 2018, an estimated 1.8 million new cases and 881,000 deaths were attributed to CRC. Even though the death rate is relatively high from this cancer, detection at an early stage is associated with better survival outcomes. Based on the Surveillance, Epidemiology, and

\footnotetext{
*Correspondence: rn03@aub.edu.lb; st29@aub.edu.lb

${ }^{1}$ Department of Internal Medicine, Faculty of Medicine, American University of Beirut, P.O. Box: 11-0236, Beirut, Lebanon

2 Department of Anatomy, Cell Biology and Physiological Sciences, Faculty of Medicine, American University of Beirut, P.O. Box: 11-0236, Beirut, Lebanon
}

End Results (SEER) Program of the National Cancer Institute (NCI) between 2010 and 2016, the percentage of diagnosed cases by stage was $38 \%$ for localized stage, $33 \%$ for regional stage, and $22 \%$ for distant stage and their reported 5-year relative survival by stage was $90.2 \%$, $71.8 \%$, and $14.3 \%$, respectively. Screening helps the diagnosis of asymptomatic CRC which are less advanced than the symptomatic ones. Present diagnostic, prognostic, and therapy predictive tests for CRC have drawbacks that affect their success. This highlights the need of novel more effective noninvasive biomarkers for CRC early detection before it progresses to distant stage as well as biomarkers for its prognosis for surveillance of recurrence or progression during treatment. original author(s) and the source, provide a link to the Creative Commons licence, and indicate if changes were made. The images or other third party material in this article are included in the article's Creative Commons licence, unless indicated otherwise in a credit line to the material. If material is not included in the article's Creative Commons licence and your intended use is not permitted by statutory regulation or exceeds the permitted use, you will need to obtain permission directly from the copyright holder. To view a copy of this licence, visit http://creativecommons.org/licenses/by/4.0/. The Creative Commons Public Domain Dedication waiver (http://creativeco mmons.org/publicdomain/zero/1.0/) applies to the data made available in this article, unless otherwise stated in a credit line to the data. 
Current research in oncology is directed at finding and evaluating biomarkers defined as biological characteristics that act as an indicator of normal biological process, carcinogenesis, or pharmacological response to a therapeutic intervention. Since solid biopsy is an invasive method that is dynamically affected by tumor heterogeneity and since radiology screening methods can pose a threat of exposure to excessive ionizing radiation, liquid biopsy as a noninvasive technique for sampling and analyzing of blood has been favored for biomarker detection. Biomarkers that are currently in use or under investigation in liquid biopsies include proteins, circulating tumor cells (CTC), circulating tumor DNA (ctDNA), circulating cell-free RNA, and exosomes [2-4]. ctDNA are of a particular interest in CRC since these fragmented DNA are readily available and offer a minimally invasive approach for tumor detection and characterization in circulation. It is postulated that ctDNA may have arisen from tumor microenvironment cells or from neoplastic tumor cells through necrosis, apoptosis, phagocytosis, or active release in the form of exosomes or lipoproteonucleotidic complex $[5,6]$. These ctDNA can be distinguished from circulating DNA originating from healthy cells by the presence of genomic aberrations that correspond to those found in the tumor, such as tumor-specific mutations or methylation. However, somatic mutations could be compromised since CRC is a heterogeneous disease and the mutations might occur at low frequency $[7,8]$. This could be overcome by detecting the epigenetic alterations of ctDNA such as DNA methylation which involves the addition of a methyl group to position 5 of the DNA cytosine ring by DNA methyltransferase enzymes and usually causes gene silencing. Interestingly, aberrant ctDNA methylation can be detected in circulation in different cancers and these ctDNA covalent modifications are more frequent and usually goes ahead many mutational changes at early stage of carcinogenesis [9]. As such, all of these characteristics along with the ease in detection render methylated ctDNA competent to be investigated as circulating biomarker. In this review, we are highlighting the studies that investigate the performance of circulating ctDNA methylation as a potential epigenetic biomarker for CRC diagnosis, prognosis, and prediction using robust statistical analysis to be translated for clinical application.

\section{Methodology}

A literature search was performed on PubMed using the following search query for each section:

- Section A: colorectal cancer AND methylation AND diagnosis AND circulating
- Section B: colorectal cancer AND methylation AND prognosis AND circulating, colorectal cancer AND methylation AND prediction AND circulating

Most of the studies discussing circulating methylated ctDNA as biomarkers for CRC diagnosis report only sensitivity and specificity that is bound by the selected cutoff point that have been considered. Accordingly, in our search in section A, we wanted to highlight the studies that can assess the performance of methylated ctDNA as biomarkers under different cutoff points using receiver operating characteristic (ROC) curve. As for reporting circulating methylated ctDNA as CRC prognostic biomarkers in section $B$, we focused on studies that reported prognostic and predictive ctDNA through robust statistical analysis according to Reporting Recommendations for Tumor Marker Prognostic Studies (REMARK) checklist [10]. This checklist addressed widespread deficiencies in the reporting of prognostic biomarker studies and particularly included details about statistical analysis showing the relation between the biomarker and the outcome (such as univariate and multivariate analysis with estimated effect like hazard ratio and survival probability).

\section{DNA methylation as a biomarker for CRC diagnosis}

Multiple screening tests for the detection of CRC have shown promising results in decreasing CRC incidence and mortality. Two important characteristics of a test are the sensitivity (or true-positive rate) and specificity (or true-negative rate) [11]. Currently, the gold-standard tool for CRC screening is colonoscopy. Although it is characterized by its high sensitivity in detecting CRC (>95\%) and precancerous lesions (88-98\% for advanced adenoma (AA)), it has some limitations including the invasiveness of the method, unpleasant lengthy bowel preparation, discomfort during the test, probability of gut perforation, infection transmission, sedation and high cost, all of which affect the patient's compliance [11, 12]. Sigmoidoscopy and computed tomography colonography (CT colonography) are other semi-invasive screening tests that show high sensitivity for detecting CRC ( $>95 \%$ and $>90 \%$, respectively) and precancerous lesions, but are also limited by unpleasant bowel preparation $[11,12]$. Noninvasive inexpensive methods include fecal immunohistochemical test (FIT) that shows higher sensitivity in detecting CRC (60-85\%) than fecal occult blood test (FOBT) that shows low sensitivity in detecting CRC (33-75\%) due to dietary restrictions and the need for multiple sampling. Although both show poor detection of precancerous lesions and high rates of false positives and false negatives, patients are easy to accept these methods because of their noninvasive characteristics and low cost. In addition, several tumor markers such 
as carcinoembryonic antigen (CEA) and carbohydrate antigen (CA19-9) have been utilized in clinical practice but show unsatisfactory results for CRC diagnosis [12]. Novel, noninvasive, sensitive tests, such as those based on the detection of aberrant DNA methylation markers in the plasma or serum have emerged to detect CRC and precancerous lesions (Table 1).

So far, Epi proColon, with its improved edition Epi proColon 2.0, is the only blood-based DNA hypermethylation screening test for CRC that has been approved by the Food and Drug Administration (FDA) [13]. This test is based on a qualitative real-time polymerase chain reaction (PCR) detection of methylated Septin 9 (mSEPT9) DNA. SEPT9 is a member of the septin gene family, a group of GTP binding protein that was first identified in yeast as key regulators of cell division. Although its role in colorectal cancer development is still not well understood, hypermethylation of SEPT9 has been reported extensively in CRC patients $[14,15]$. Other tests have also been utilized to analyze the methylation status of SEPT9 as an individual marker or in combination with other markers. These include ColoDefense, MethyLight, and Heavy MethyLight assays that rely on the quantitative methylation-specific real-time PCR (qMSP) detection. Sensitivity of the analyzed mSEPT9 in plasma/ serum ranged from 47 to $87 \%$ with a specificity ranging from 89 to $98 \%$ in a wide variety of studies [13, 16-28]. Sensitivity of mSEPT9 gradually increased with higher stages and was reported to be $100 \%$ in stage IV CRC patients in some studies, however, remaining low in early stages (I-II) [16, 17, 22, 27, 28]. Notably, SEPT9 methylation showed higher sensitivity in diagnosing CRC than the conventional markers CEA and CA-19-9, or even FOBT $[18,19,25]$, and when combining mSEPT9 with either one of them, diagnostic sensitivity, especially for early stages, increased $[18,25,26]$. Furthermore, sensitivity of $\mathrm{mSEPT} 9$ for the detection of adenomas and polyps was relatively low in most studies, ranging from 8 to $40 \%$ [17-19, 21, 23, 24, 28]. Most of these studies used the $1 / 3$ algorithm, which means that the sample is considered positive if one of three PCR replicates is positive. However, a recent study by Song et al. reported a high positive detection rate (PDR) in villous adenoma and adenoma with high-grade dysplasia $(83.3 \%$ and $62.5 \%$, respectively), although the rate for all adenomas was much lower (31.8\%) [27]. In this study, they used the $2 / 3$ algorithm, which might explain the difference in the obtained results. A recent study detected 10 different methylation subregions within the SEPT9 gene at a sensitivity of $84.9 \%$ and a specificity of $83.3 \%$ (Area under the curve, AUC $=0.882$ ) in a cohort of 53 CRC patients, 48 patients with AA, 30 patients with benign polyps, and 48 healthy controls. To compare whether this multi-marker approach produced better detection of early-stage CRC and precancerous lesions from the usual single-marker approach that is commercially used, a new cohort of 43 CRC patients, 15 patients with AA, 15 patients with benign polyps, and 30 controls was recruited. Both approaches had the same high specificity (90\%). When compared with the usual single-marker approach, the sensitivity of the multi-marker approach was higher for early-stage CRC $(73.3 \%$ vs. $60 \%$ for stage I, $76.5 \%$ vs. $70.6 \%$ for stage II) and was statistically higher for AA and polyps $(53.3 \%$ vs. $26.7 \%$ for AA, $33.3 \%$ vs. $6.7 \%$ for polyps) [29].

Other defined markers for CRC detection described in more than one study include methylated $B C A T 1$ (branched-chain amino acid transaminase 1), IKZF1 (IKAROS family zinc finger 1), SDC2 (syndecan-2), ALX4 (aristaless-like homeobox 4), SFRP2 (secreted frizzledrelated protein 2), OSMR (oncostatin M receptor), SFRP1 (secreted frizzled-related protein 1), and VIM (vimentin). Methylation of $B C A T 1$ and $I K Z F 1$ is regularly described together. $B C A T 1$ gene encodes an enzyme involved in catabolism of branched-chain amino acids and IKZFI gene encodes a transcription factor that regulates a small set of cell cycle-regulator genes [30, 31]. Sensitivity of $B C A T 1$ ranged between 47.3 and $64.9 \%$ and that of IKZF1 ranged between 48 and $67.6 \%$ for CRC detection. In addition, the positivity rates increased with higher CRC stages but were very low for adenomas [32-34]. Another reported gene, $S D C 2$, promotes cell proliferation, migration, and invasion, inhibits apoptosis, and activates epithelial to mesenchymal transition (EMT) and mitogen-activated protein kinase (MAPK) signaling pathways in CRC cells [35]. SDC2 might be a highly promising methylation marker for CRC detection where it displayed a sensitivity that ranged between 69 and $87 \%$ for all stages and a specificity of approximately $95 \%$ in the plasma/serum of CRC patients. Recent studies showed that the PDR of $S D C 2$ methylation test increased with higher tumor stage, ranging between 55 and 100\% for stages I-IV $[16,17,36]$. In addition, methylation of $A L X 4$, a transcription factor involved in limb and skull development, was more frequently found in the serum of CRC patients compared to normal individuals (sensitivity of $83.3 \%$, specificity of $70 \%, A U C=0.839$ ) [37]. Methylation of another gene, SFRP2, a member of the SFRP family that act as soluble modulators of Wnt signaling, is also reported as a potential marker for CRC detection. SFRP2 methylation analysis showed a sensitivity of $63.8 / 69.4 \%$ for CRC detection and $42.9 \% / 81.8 \%$ for adenoma detection [38, 39]. Compared to SEPT9, sensitivity of SFRP2 for AA detection is much higher suggesting that SFRP2 might be a viable biomarker for the detection of precancerous lesions. OSMR is reported as a tumor suppressor 


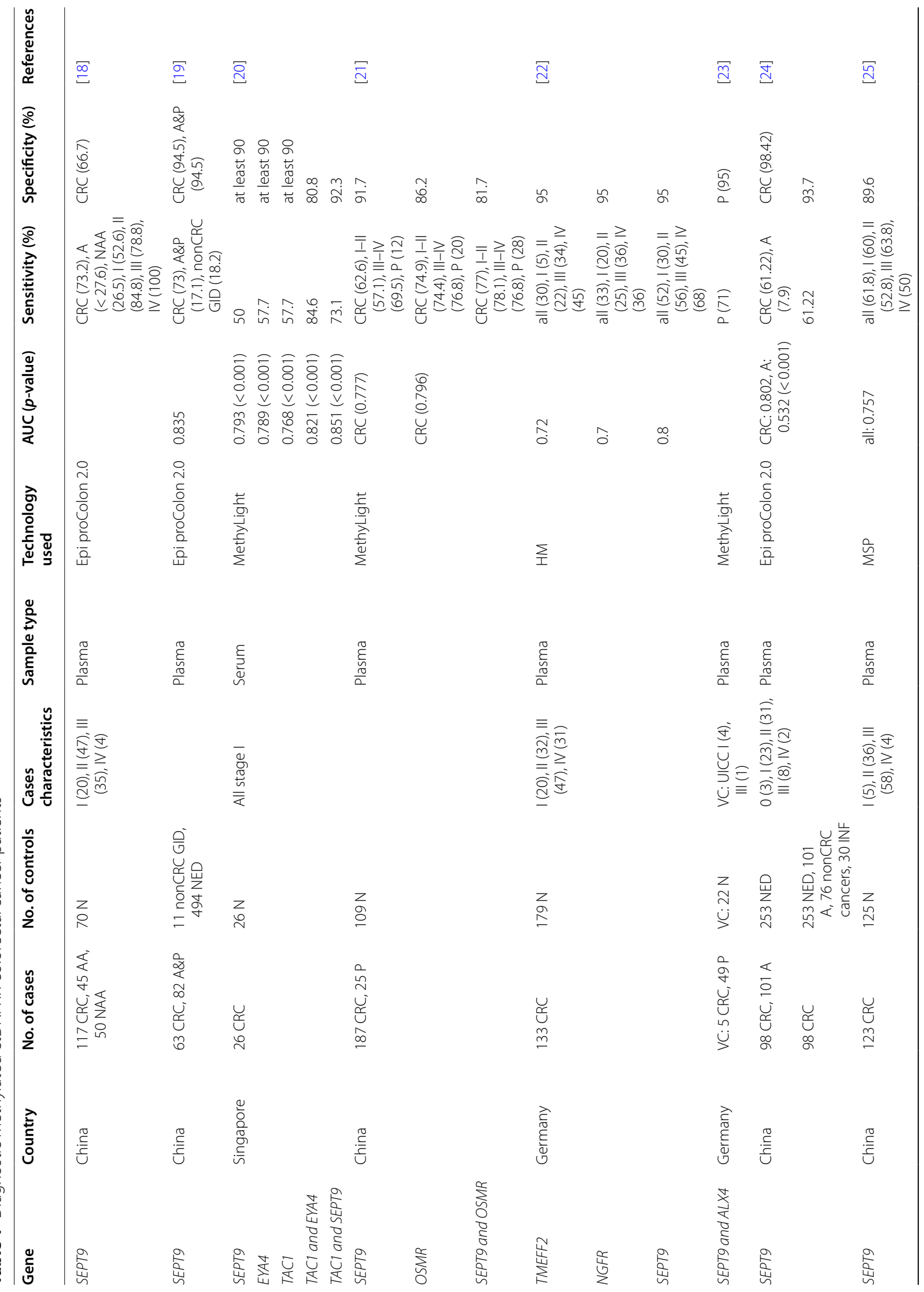


Nassar et al. Clin Epigenet ～(2021) 13:111

Page 5 of 25

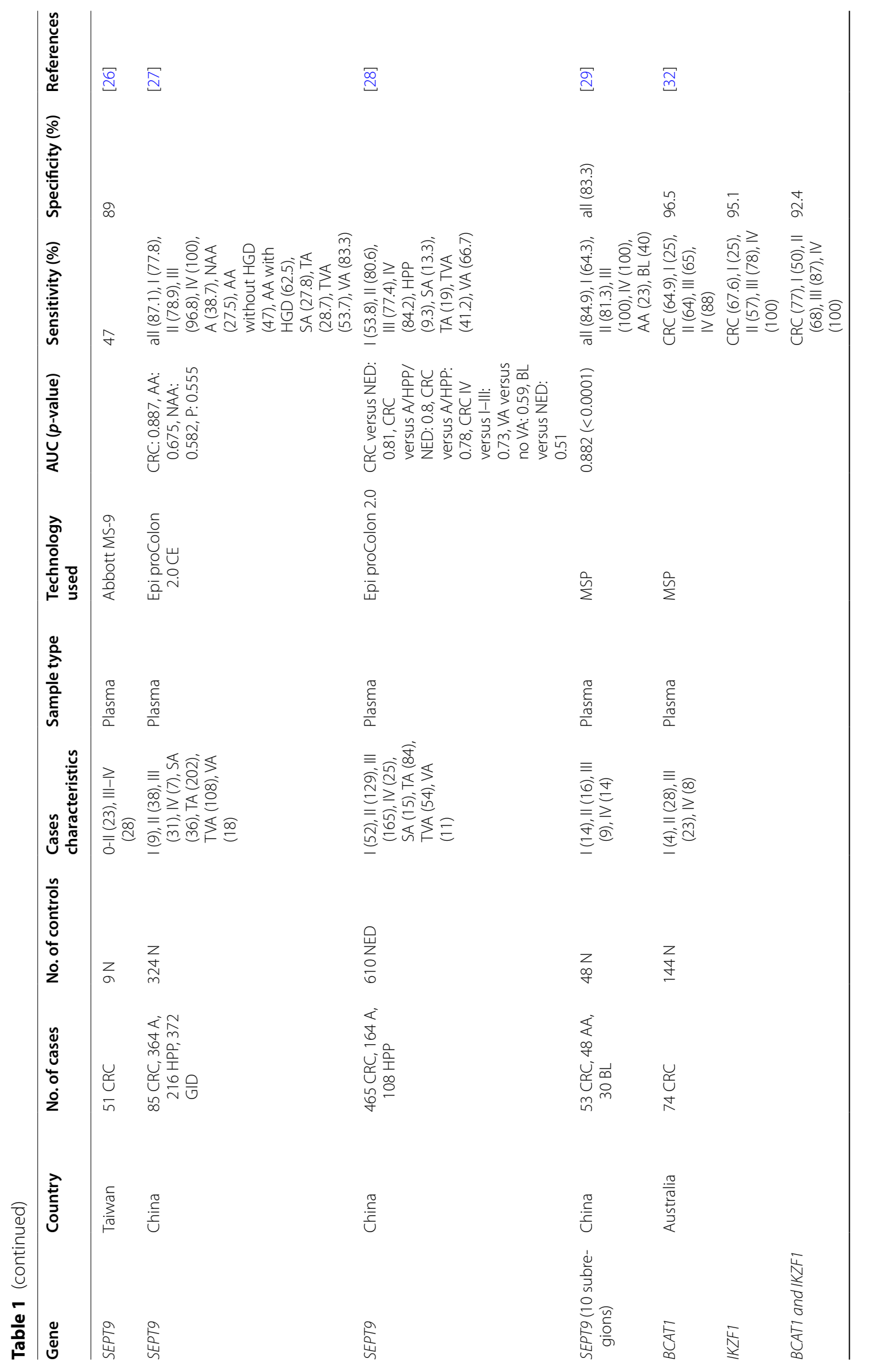


Nassar et al. Clin Epigenet $\quad$ (2021) 13:111

Page 6 of 25

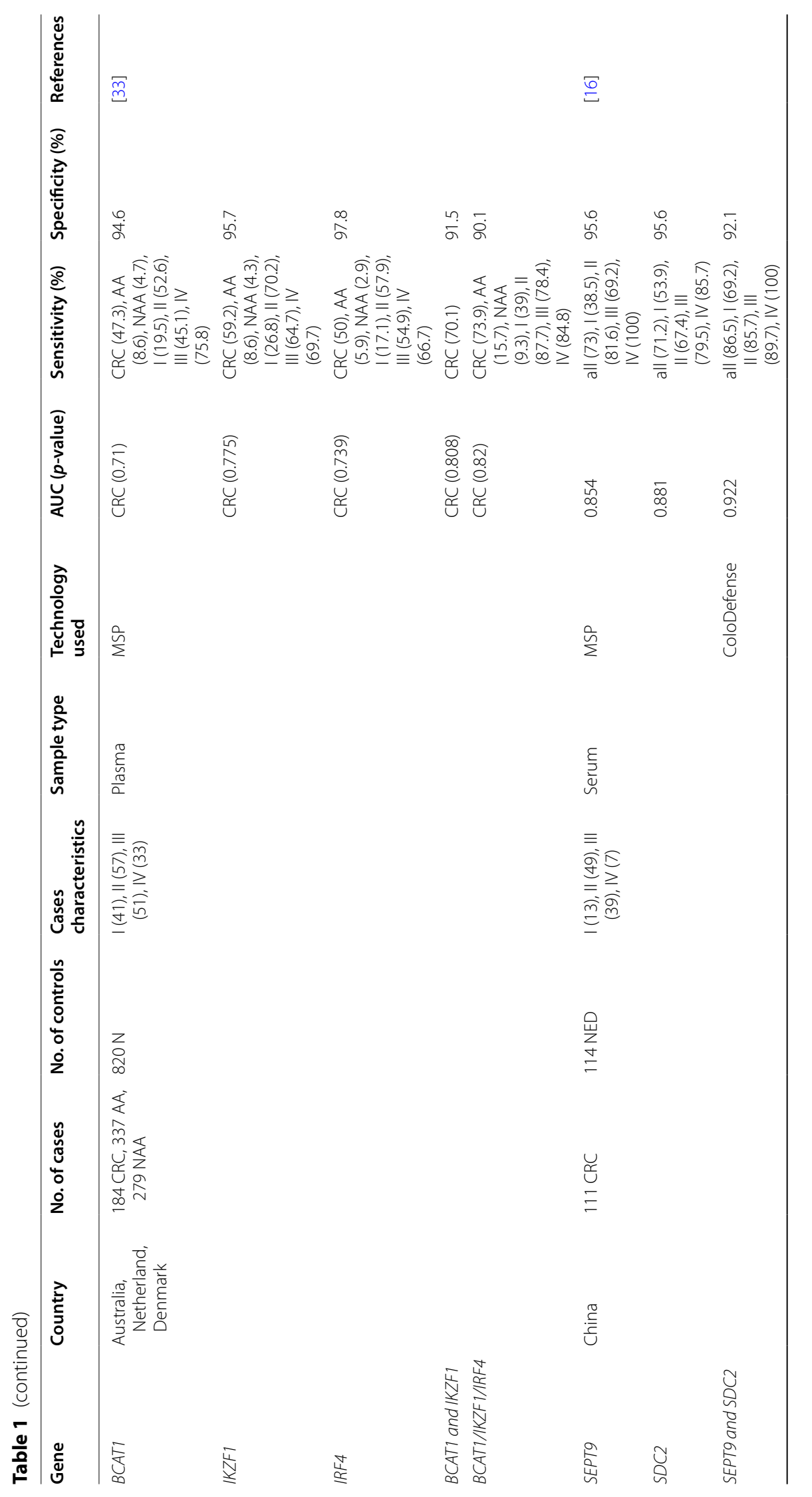




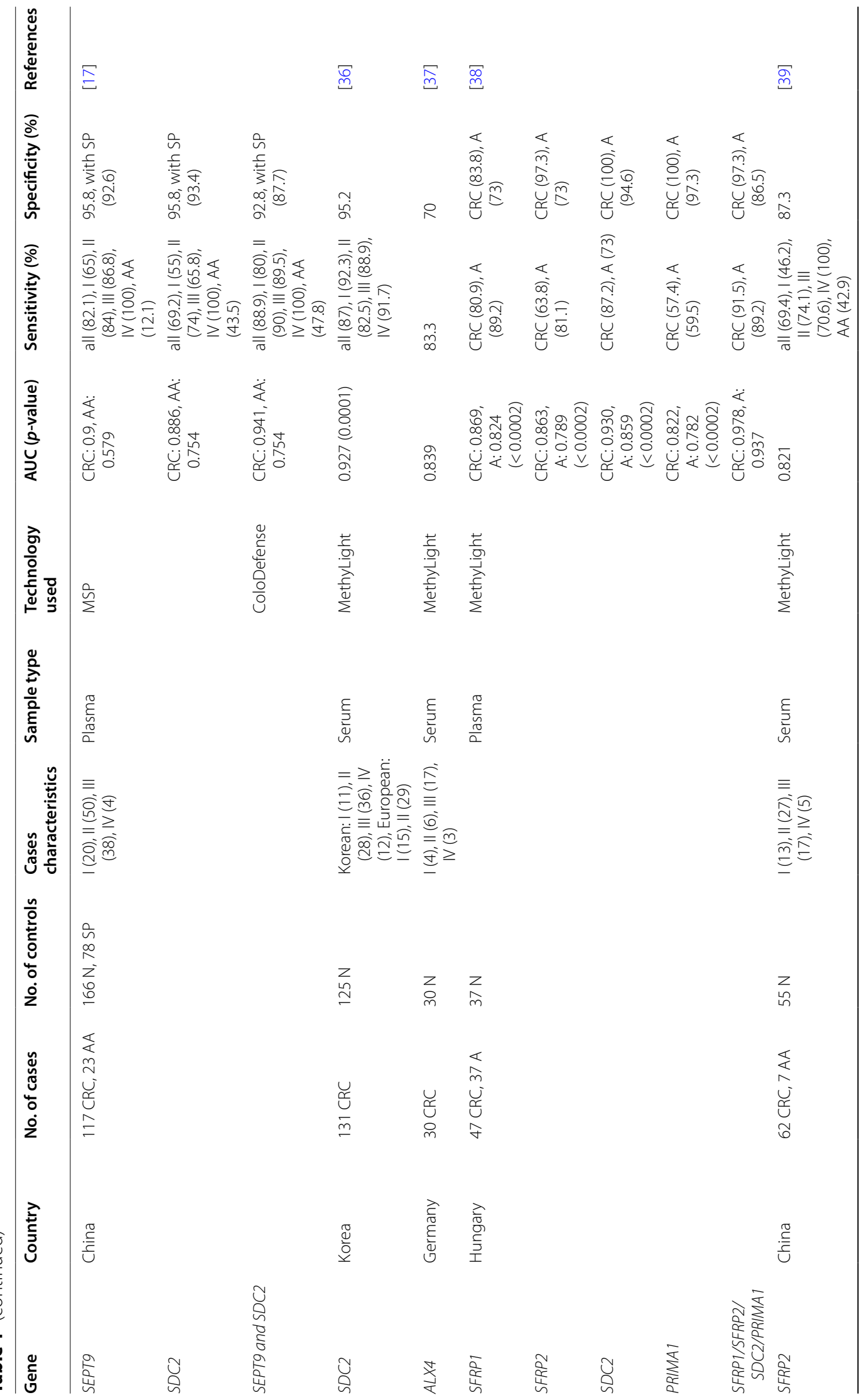




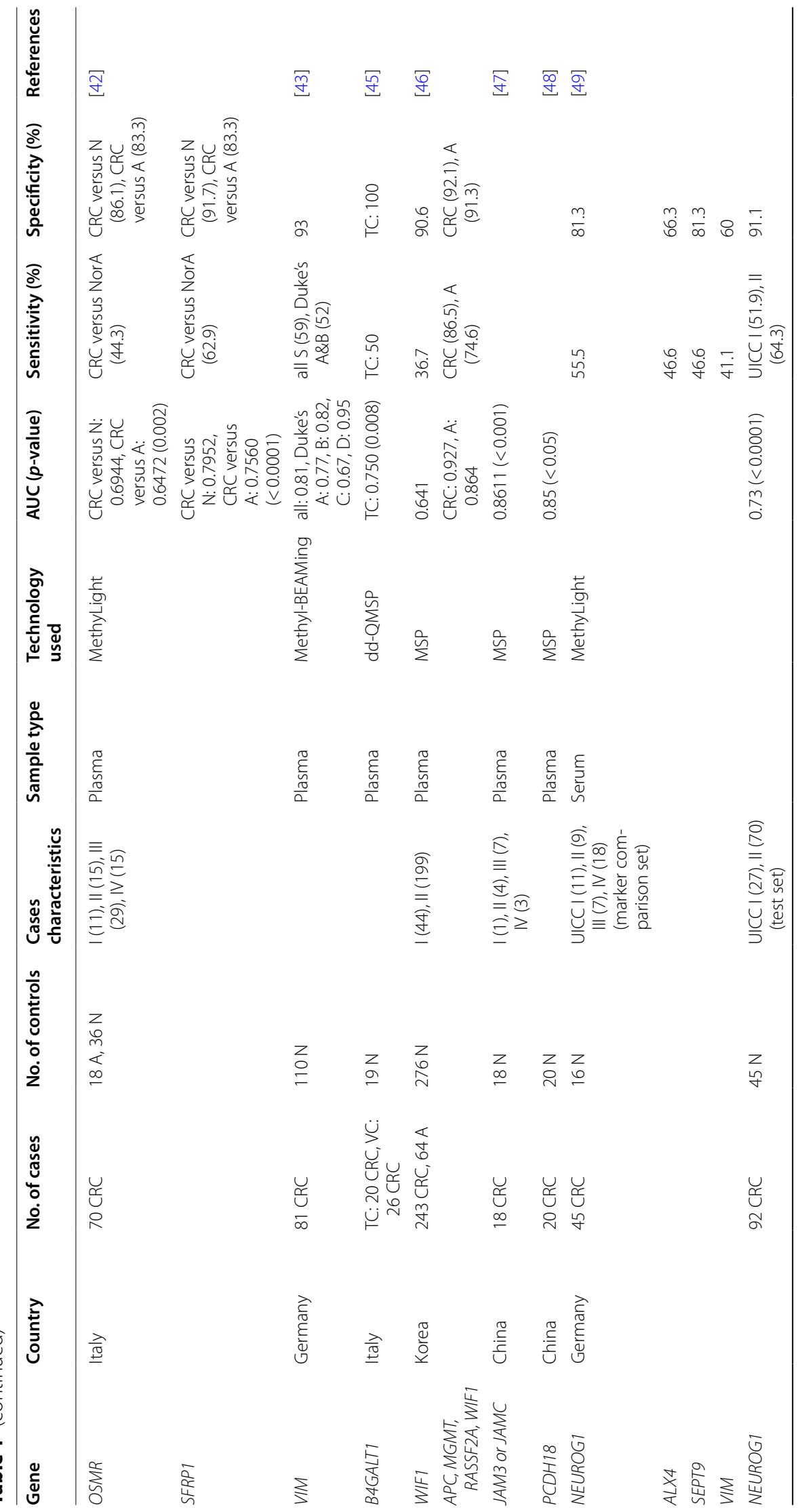




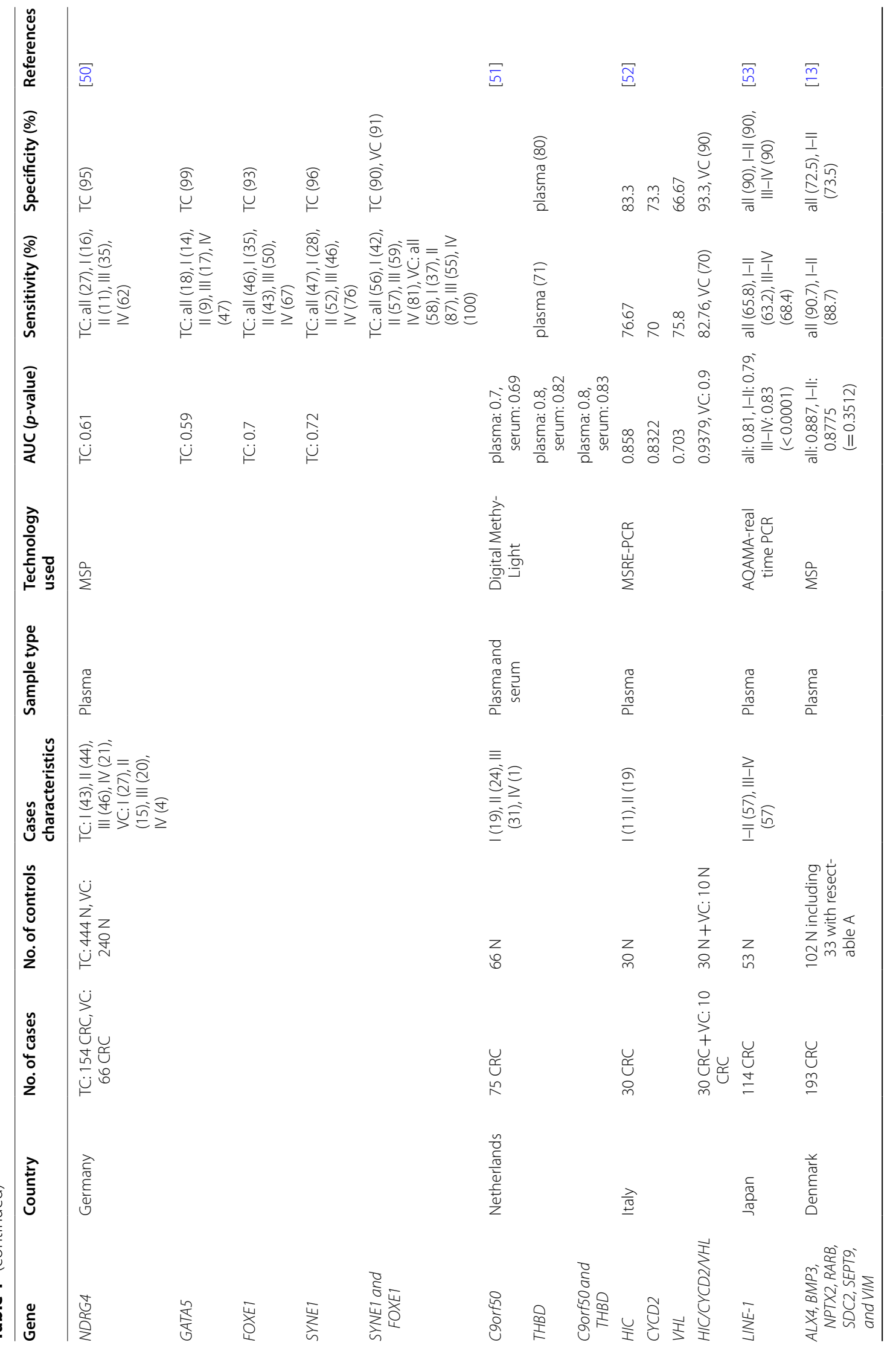




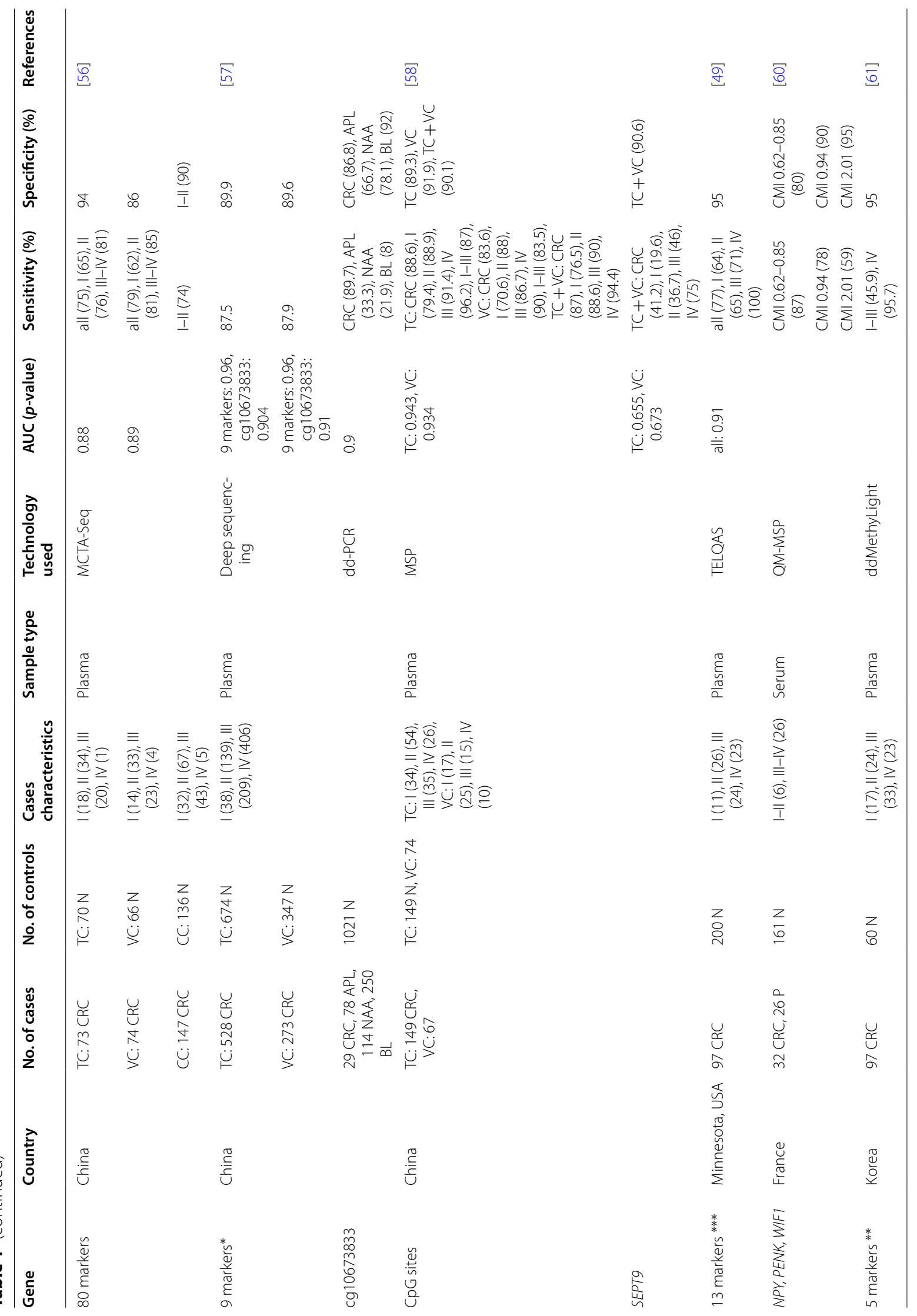




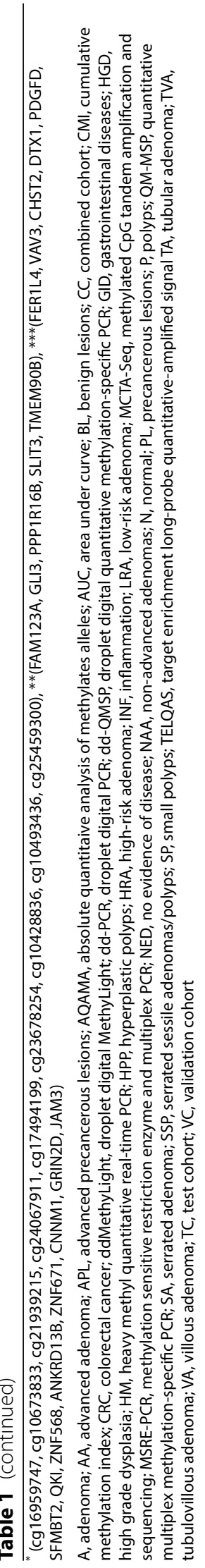


in colon cancer progression; promoter methylation correlated with loss of OSMR expression in CRC cells and low expression of OSMR was associated with resistance to growth inhibition [40]. Another gene, SFRP1, is a tumor suppressor gene that inhibits cell proliferation, migration, and invasion, and mediates apoptosis of CRC cells [41]. Methylation of OSMR and SFRP1 genes was shown to be significantly higher in CRC and adenoma than in normal plasma samples [21, 42]. Furthermore, VIM gene, a target of epigenetic modifications, is frequently methylated in CRC. VIM methylation was shown to be higher in CRC plasma compared to normal samples with a sensitivity of $59 \%$ and specificity of $93 \%$ (AUC $=0.81$ ) [43]. All mentioned markers are reported to be methylated in CRC tissues, blood, and/or stools [44]. Overall, these markers showed promising results in the detection of CRC and thus require further validation in larger cohorts. Other less frequently described candidate markers that require further investigation and validation include B4GALT1 [45], WIF1 [46], JAM3 [47], EYA4 and TAC1 [20], PCDH18 [48], NEUROG1 [49], TMEFF2 and NGFR [22], NDRG4, GATA5, FOXE1, and SYNE1 [50], C9orf50 and THBD [51], HIC, CYCD2, and VHL [52], and hypomethylated LINE-1 [53].

Several studies investigated the diagnostic performance of a panel of methylated genes and showed that the simultaneous analysis of multiple hypermethylated circulating DNA is more sensitive in detecting CRC than the individual markers. Multiple studies showed that a panel of methylated genes containing $\mathrm{mSEPT} 9$ might be promising in the detection of precancerous lesions and earlystage CRC. The simultaneous analysis of methylated SEPT9 and SDC2 increased the sensitivity for all stages and for each stage without significant effect on specificity $[16,17]$. In addition, sensitivity of AA detection was higher for the combinatorial markers (47.8\%) than for each marker individually $(12.1 \%$ for SEPT 9 and $43.5 \%$ for $S D C 2)$ [17]. These studies have shown that methylated SEPT9 and SDC2 panel might be one of the best combinations for early CRC screening. Analysis of BCAT1 and $I K Z F 1$, simultaneously, showed a sensitivity of $77 \%$ for CRC at a specificity of $92.4 \%$. This model improved the detection rate of CRC with a small decrease in the specificity (BCAT1 sensitivity: $64.9 \%$, specificity: $96.5 \%$; IKZF1 sensitivity: 67.6\%, specificity: 95.1\%) [32]. A recent study reported the test performance of different methylation target combinations (BCAT1/IKZF1, BCAT1/ IRF4 (Interferon regulatory factor 4), IKZF1/IRF4, and $B C A T 1 / I K Z F 1 / I R F 4)$ and showed that the best sensitivity $(73.9 \%)$ was achieved using the three gene markers (BCAT1/IKZF1/IRF4) with a specificity of $90.1 \%$ and an AUC of 0.82. In addition, the positivity rates for detecting AA and non-advanced adenoma (NAA) were the highest in this panel although remaining very low $(15.7 \%$ for AA, 9.3\% for NAA) [33]. However, more than one study showed that the use of a single positive PCR replicate for methylated $B C A T 1$ can yield false positive results [33, 54]. To overcome this, Young et al. used a "BCAT1 replicate rule" that states that a specimen is positive if at least two PCR replicates were positive for $B C A T 1$ (along with at least one positive PCR replicate for IKZF1 or IRF4). In this way, the false-positive rate for CRC significantly decreased from 9.9 to $5.9 \%$ without any significant effect on sensitivity, but it significantly decreased the sensitivity of AA detection from 15.7 to $11 \%$ [33]. Furthermore, age ( $\geq 70$ years) and cell free DNA yield were significant independent factors associated with the detection of methylated $B C A T 1 / I K Z F 1$ in the patients with no CRC [54]. Another study showed low sensitivity of BCAT1/ IKZF1 in detecting sessile serrated adenomas/polyps (SSP) $(8.8 \%)$ and when combined with FIT, it remained low (26.5\%) but still higher than FIT alone (16.3\%) [55].

The combined analysis of $A L X 4, B M P 3$ (bone morphogenetic protein 3), NPTX2 (neuronal pentraxin 2), $R A R B$ (retinoic acid receptor beta), SDC2, SEPT9, and VIM displayed a sensitivity of $90.7 \%$ for all CRC stages and $88.7 \%$ for stages I/II using a model accounting for the covariates female gender and age greater than 66 years however, with a $p$ value $>0.05$ [13]. This logistic regression model was considered the most applicable among 17 developed models in the study since it contained a limited number of genes and it did not differ from the model produced by another method which is Penalized regression using Firth's method. Interestingly, in this study, they showed the low sensitivity to some individual markers, reiterating the importance of a panel of genes as diagnostic biomarkers [13]. Moreover, Tanzer et al. proved that the combined analysis of methylated SEPT9 and ALX4 was highly significant in the detection of advanced precancerous colorectal lesions with a $71 \%$ sensitivity and a $95 \%$ specificity. This study presents an approach for the detection of precancerous lesions using methylated markers in plasma of CRC patients; however, it should be validated on a larger cohort [23]. In addition, a panel of 80 hypermethylated markers detected by methylated CpG tandem amplification and sequencing (MCTA-Seq) method distinguished early-stage CRC patients from normal individuals with $74 \%$ clinical sensitivity and $90 \%$ specificity. These markers included known ones like SEPT9 and IKZF1 and novel ones including TJP2 (tight junction protein 2) and GATM (glycine amidinotransferase, mitochondrial) [56]. Another study distinguished CRC from normal controls through 9 methylated markers with $87.5 \%$ sensitivity and $89.9 \%$ specificity $(\mathrm{AUC}=0.96)$ in the training cohort, and $87.9 \%$ sensitivity and $89.6 \%$ specificity $(\mathrm{AUC}=0.96)$ in the 
validation cohort, by constructing a combined diagnostic score (cd-score). They then showed that cg10673833 displayed the best diagnostic performance with AUC of 0.904 and 0.91 for training and validation cohort, respectively [57]. Moreover, Sui et al. reported that the methylation of specific $\mathrm{CpG}$ sites in plasma can be used as an early CRC detection model. The selected CpG sites were based on enrichment of CRC-related methylated variation signal, based on the $450 \mathrm{~K}$ microarray data of CRC samples, normal samples and white blood cells from The Cancer Genome Atlas (TCGA) and Gene Expression Omnibus (GEO) datasets. These ctDNA methylation markers had a sensitivity of $88.6 \%$ and a specificity of $89.3 \%$ (AUC $=0.943$ ) in a training set composed of 149 CRC and 149 healthy controls, and a sensitivity of $83.6 \%$ and a specificity of $91.9 \%(\mathrm{AUC}=0.934)$ in the test set composed of $67 \mathrm{CRC}$ and 74 healthy controls. The sensitivity increased with higher CRC stages in both the training and test sets. The performance of the model in the unmatched population was similar to that of the matched population in detecting the different CRC stages. In addition, this model had higher sensitivity when compared to SEPT9 model (41.2\%) with a comparable specificity making it a more promising approach in the early detection of CRC [58]. In addition, a panel of 13 methylated DNA markers (FER1L4, VAV3, CHST2, DTX1, PDGFD, SMBT2, QKI, ZNF568, ANKRD13B, ZNF671, CNNM1, GRN2D, and JAM3), in the plasma of 97 CRC and 200 controls, detected all stages of CRC with a sensitivity of $77 \%$, a specificity of $95 \%$, and AUC of 0.91 , higher than that of each marker and than that of CEA. Upon adding CEA to the panel, AUC did not improve [59]. Moreover, a panel consisting of methylated SFRP1, SFRP2, SDC2, and PRIMA1 (proline-rich membrane anchor 1) genes might allow noninvasive detection of colorectal adenoma and cancer from plasma samples, where they displayed higher sensitivities than that of the individual genes. This panel distinguished CRC patients $(\mathrm{n}=47)$ from normal ones $(\mathrm{n}=37)$ with a $91.5 \%$ sensitivity and a $97.3 \%$ specificity (AUC $=0.978)$, and adenoma samples $(\mathrm{n}=37)$ with a sensitivity of $89.2 \%$ and specificity of $86.5 \%(\mathrm{AUC}=0.937$ ) [38]. Other described panels that might be valuable diagnostic biomarkers for CRC detection include SEPT9 and OSMR [21], SEPT9 and TAC1 [20], HIC/CYCD2/VHL [52], APC/MGMT/RASSF2A/WIF1 [46], SYNE1 and FOXE1 [50], WIF1/NPY/PENK [60], THBD and C9orf50 [51], and FAM123A/GLI3/PPP1R16B/SLIT3/TMEM9OB [61]. Overall, these studies have shown that the use of marker panels is of high accuracy in the detection of CRC and is more promising than the use of single markers.

Most of the studies analyzed methylation status of the genes in CRC tissues by microarray analysis, Illumina methylation array, or MSP then, validated the results in the plasma and/or serum by MSP dependent assays. Several studies reported different sensitivities/specificities of the same diagnostic methylated marker. Differences in marker performance might be due to differences in ethnicity, choice of control population, sample type, or DNA extraction methods. Other frequently reported markers include APC, CDKN2A, HLTF, MLH1, HPP1, $R U N X 3$, and $S H O X 2$, and less frequently described markers include TMEM240, AKAP12, BNC1, BRCA1, CDH1, CDH4, CRABP1, DAPK1, DLC1, ERCC1, FBN2, FGF2, FHIT, GRASP, IRF4, ITGA4, LRR3CB, MAL, NELL1, PCDH10, PDX1, PHACTR3, PPENK, RASSF1A, SMAD4, SOX21, SPG20, SST, TFPI1, and WNT5A, some of which showed high sensitivities, therefore, supporting their further investigation and validation [62]. These markers, along with the previously described ones, were investigated in multiple studies, but we did not include them since ROC curves were not established to validate their diagnostic performance.

\section{DNA methylation as a biomarker for CRC prognosis and prediction}

DNA methylation has been also explored as a potential biomarker for CRC prognosis and therapy prediction whereby it can predict the overall cancer outcome and recurrence of the disease as well as the effectiveness of a treatment. Most of current CRC prognostic and predictive biomarkers are mainly tissue derived and vary due to intratumoral heterogeneity as well as heterogeneity between metastases. Increased prognostic severity of CRC has been identified with increase in tumor tissue staging (TNM staging), presence of $B R A F$ mutation especially V600 mutation [63], microsatellite stability due to activation of the mismatch repair genes as compared to microsatellite instability [64], and presence of mutations in SMAD4 and APC genes [65, 66]. However, analysis of multiple biopsies is not feasible in the clinical routine, and this is unsuitable for neoadjuvant treatment decisions which makes these markers inefficient. Computed tomography is a method for disease assessment, but it cannot be used routinely since this radiation method cannot be repeated frequently as an instant test.

As for blood markers, higher ctDNA levels (especially KRAS, APC and TP53 mutations) have been reported with poor outcome $[67,68]$ and elevated neutrophil-tolymphocyte ratio has been associated with short overall survival (OS) and progression-free survival (PFS) after treatment in CRC patients [69, 70]. However, CEA is the main current serum marker to assess recurrence especially every 3 months post-surgery for CRC patients with stage II or III [71] or to have intensive follow-up every 3-6 months for CRC along with CT every 3-12 months [72]. CEA is more sensitive to advanced stage CRC than 
early stage CRC, which restricts its use for many surgical patients [73]. Despite these examinations, novel prognostic, and predictive biomarkers such as methylated ctDNA that are easily detected are needed (Table 2).

The HPP1 gene (hyperplastic polyposis 1) encodes a transmembrane protein that is frequently methylated in colorectal tumors [74]. Another gene HLTF (helicase-like transcription factor) encodes for a SWI/SNF family protein with both helicase and E3 ubiquitin ligase activities and is also common target for methylation and epigenetic gene silencing in colon cancer [75]. Both methylated ctDNAs of these genes were extensively studied prospectively pretherapy in the serum of CRC patients in several cohorts. They were associated with low OS especially in stage IV CRC [76, 77]. In another study, methylation of HLTF and HPP1 in serum were significantly correlated not only with more advanced stages of CRC but also with high levels of lactate dehydrogenase (LDH) release as a surrogate marker for cell damage [78]. Moreover, plasma levels of methylated HPP1 (mHPP1) ctDNA in a large cohort of metastatic CRC patients was detected before treatment with a combination therapy containing a fluoropyrimidine, oxaliplatin and bevacizumab and then became undetectable after 2-3 weeks of therapy [79]. The baseline level of $M H P P 1 \mathrm{ctDNA}$ correlates with poor OS, while its low level after the first treatment correlated with reduced risk of progression. $\mathrm{m} H P P 1 \mathrm{ctDNA}$ differentiates between responders and non-responders to therapy as determined by the radiological staging after 12 or 24 weeks (AUC $=0.77$ or 0.71 , respectively). Hence, mHPP1 ctDNA might be a predictive biomarker for monitoring response to first-line therapy and switching therapy protocols even before doing radiological staging. Furthermore, methylated HLTF ctDNA in pretherapy sera of 106 patients curatively resected for CRC were associated with poor outcome and a relative risk of disease recurrence [80]. Hence, it was concluded as a predictor of disease recurrence in CRC even though with Philipp et al. 2012, mHLTF ctDNA failed to detect identify high risk groups in the UICC II and III subgroups [76].

Methylated SEPT9 (mSEPT9) ctDNA has been also discussed as a prognostic and predictive CRC biomarker. High levels of mSEPT9 ctDNA is a prominent biomarker for CRC recurrence as shown by more than one study $[19,81]$. Elevated level mSEPT9 detected in postoperative sera of CRC patients (stages I-III) after one year followup and its dynamic change from one week before surgery to last follow-up were found to be an independent predictor of tumor recurrence [81]. mSEPT9 was even a better biomarker for recurrence than CEA where its level at one year showed an earlier lead time advantage of more than 2 months compared to concurrent serum
CEA. The combined detection of mSEPT9 and contrast enhanced CT enhanced the sensitivity (positive detection rate for both is $95.2 \%$ ) for recurrence monitoring in CRC after radical surgical resection [19]. Furthermore, hypermethylation of SEPT9 in the plasma of postoperative CRC patients was associated with lower OS and its dynamic increment after surgery correlated with a higher mortality rate and the presence of metastasis [18]. A recent study on $\mathrm{mSEPT} 9$ that used multiple probes for 10 selected subregions of SEPT9 revealed that positive detection of these markers in postoperative (within 2 weeks) plasma of CRC patients associate with poorer recurrence-free survival. The capacity of these mSEPT9 markers to predict recurrence did not change upon stratifying the patients according their use of adjuvant chemotherapy but it was affected when dividing patients according to stage (localized, stage II, or stage III CRC) [29]. Detection of positive mSEPT9 ctDNA in the plasma of CRC patients even at baseline before surgery was correlated with higher risk of death after surgery and shorter PFS and OS [82, 83].

In addition, $N P Y$ gene (neuropeptide $\mathrm{Y}$ ) is methylated at high frequency in CRC [84] and it encodes a neuropeptide involved in cell motion and proliferation in CRC [85]. High baseline levels of methylated NPY (mNPY) ctDNA in plasma of metastatic CRC patients before treatment with regorafenib, oral multi-kinase inhibitor, was correlated with shorter OS. Its measurement was shown to be better even than measuring mutated $R A S / R A F$ ctDNA since it could be measured in almost all patients irrespective of mutational status [86]. Changes in the longitudinal levels of $\mathrm{mNPY}$ ctDNA in these metastatic CRC may predict early effect and later progression which is in line with Garrigou et al. who was the first to analyze the hypermethylation of $N P Y$ ctDNA in different stages of CRC in a follow up setting [87]. A recent study revealed that high levels of $\mathrm{mNPY}$ ctDNA in pretherapy serum samples taken from locally advanced rectal cancer patients was correlated with higher risk of death and distant disease [88]. Additionally, elevated levels of $\mathrm{m} N P Y$ in plasma of metastatic CRC patients before treatment with 5-fluorouracil, oxaliplatin, and bevacizumab was also correlated with shorter OS and PFS [89]. Another studied methylated ctDNA is that of RASSF1A gene (RAS association domain family protein 1 ) which is a tumor suppressor thought to regulate cell proliferation and apoptosis and its expression is reported to be lost in CRC mainly by hypermethylation $[90,91]$. Promoter methylation of RASSF1A in blood was reported to be a prognostic biomarker for patients with stage II and III CRC treated with oxaliplatin-based chemotherapy [92]. Similar results were also identified in serum but with more pronounced negative impact on survival of metastatic CRC patients [93]. 


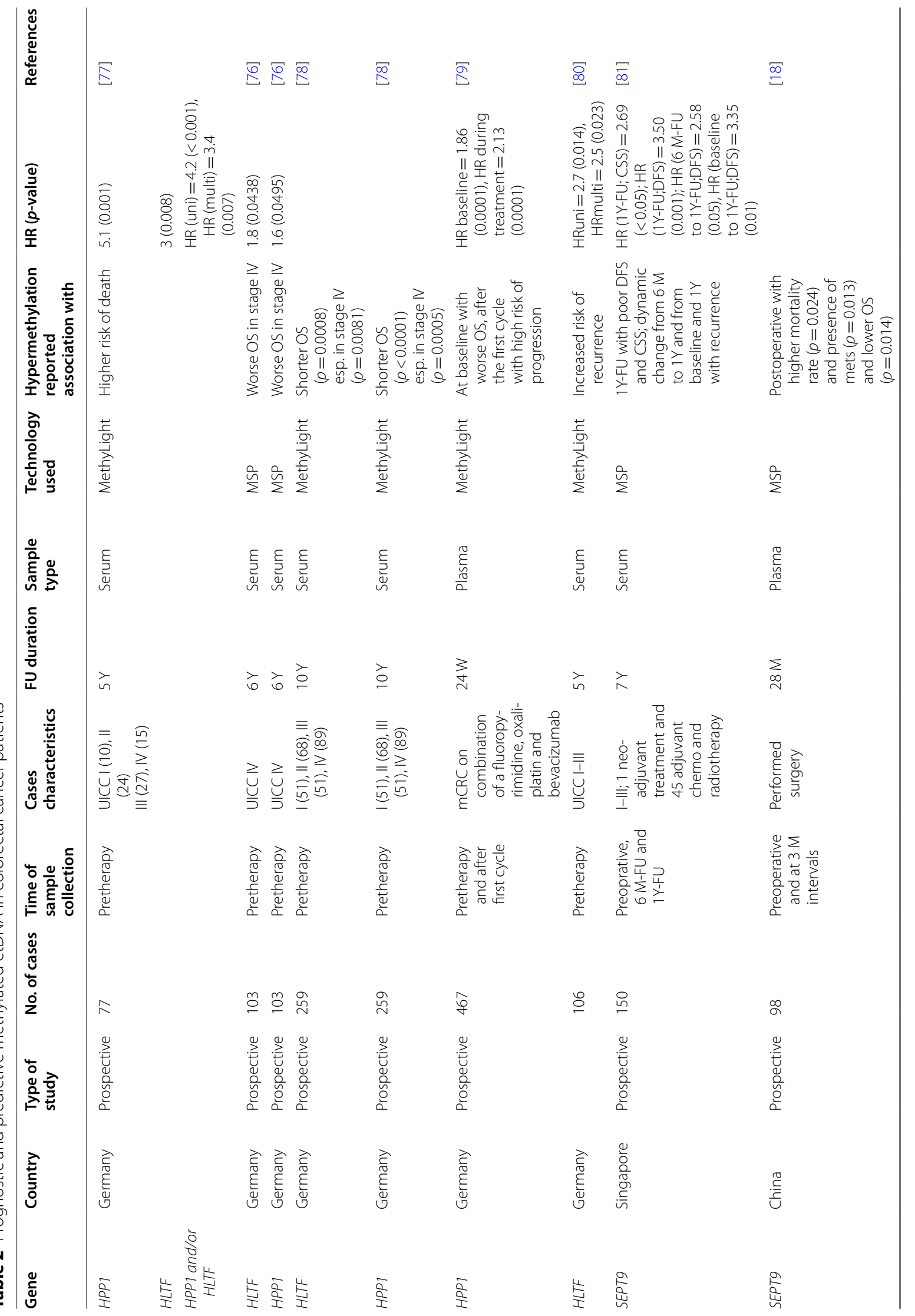




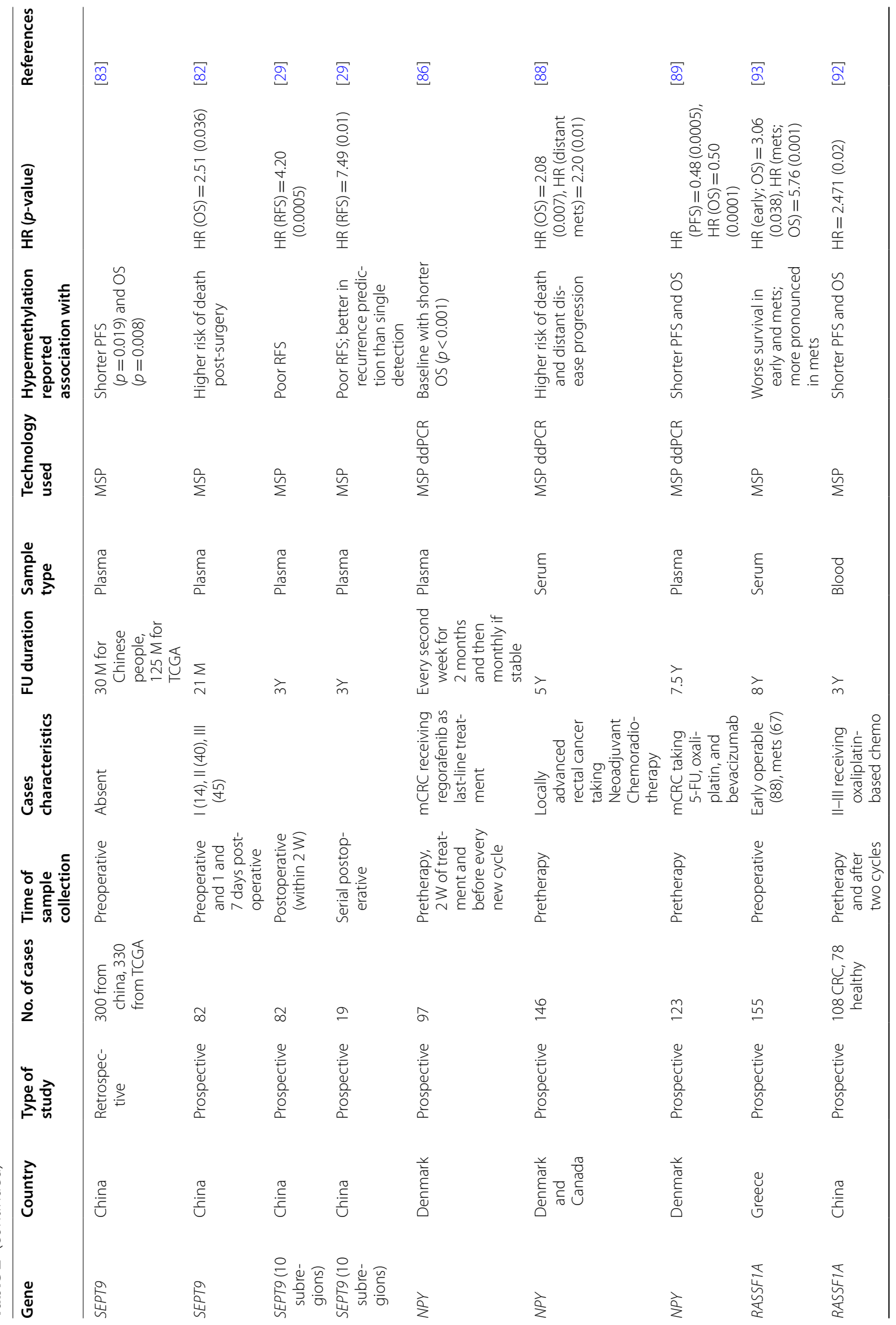




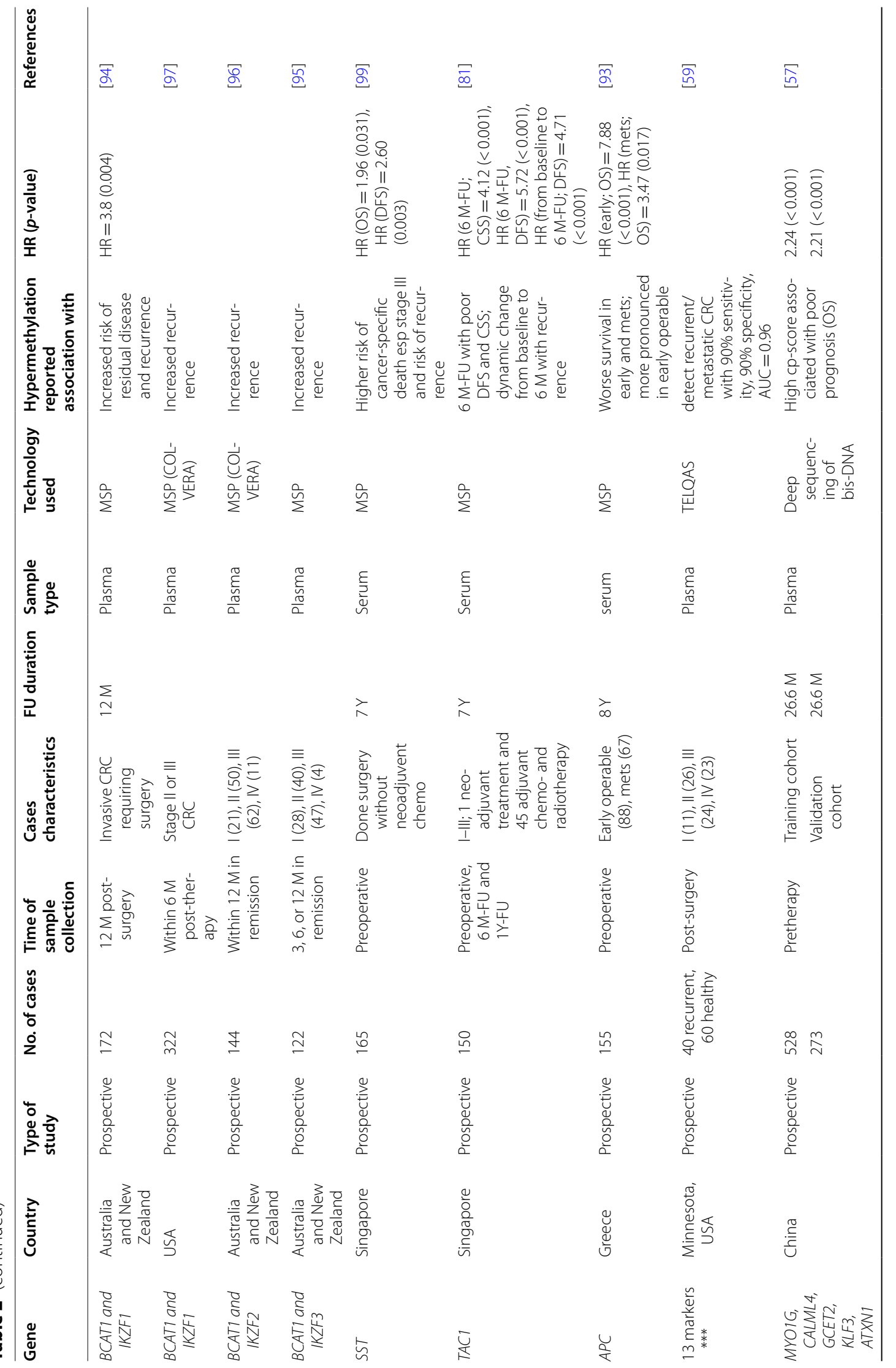




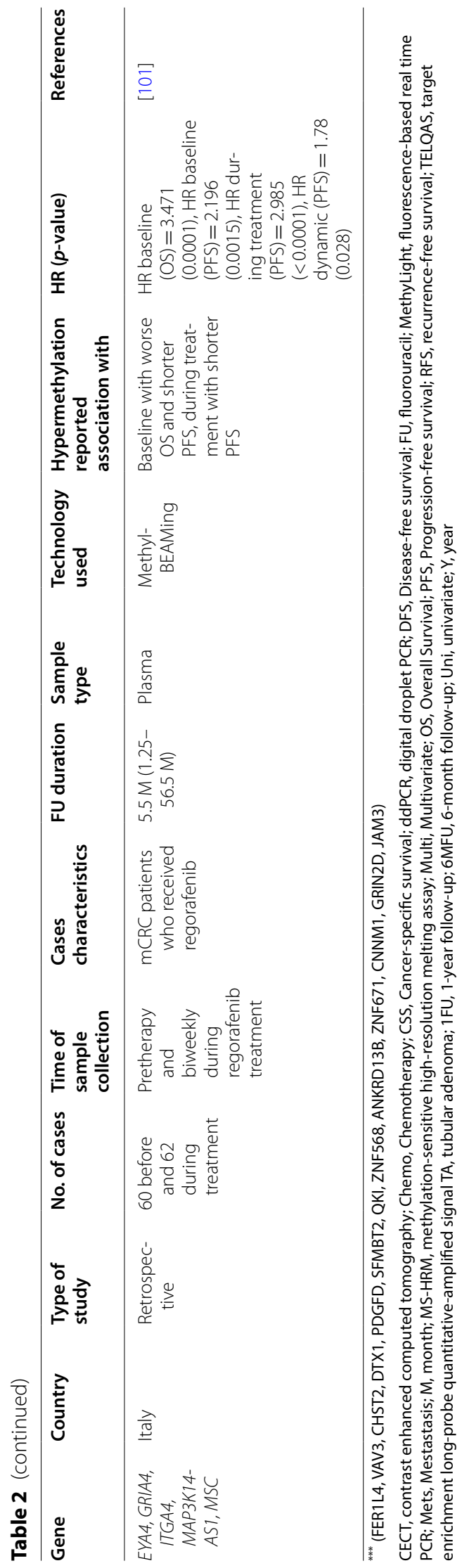


Hypermethylation of these two genes IKZF1 and $B C A T 1$ in plasma of CRC patients after surgery increased their risk of residual disease and subsequently the risk of recurrence [94]. Several studies have explored the use of these 2 methylated ctDNA in plasma of CRC patients who are in remission or after treatment in order to detect recurrence [95-97]. The sensitivity and the odds ratio of these two methylated ctDNA test for recurrence were significantly higher than the sensitivity of CEA. Upon adjusting for other predictors of the presence of recurrence, a positive methylated ctDNA of $B C A T 1$ and $I K Z F 1$ was an independent predictor (odds ratio, 155.7; 95\% CI, 17.9-1360.6; $p<0.001$ ) in plasma of CRC patients either during surveillance or within 12 months of the confirmation of recurrence [96].

Other prognostic and predictive methylated ctDNA biomarkers that were mentioned only in a single study were methylated ctDNA of somatostatin (SST), tachykinin-1 (TAC1) and adenomatous polyposis coli (APC). Two genes that are usually downregulated in CRC were studied as circulating methylated biomarker: SST gene encodes a well-characterized gastrointestinal neuroendocrine and growth regulatory peptide that acts as a tumor suppressor gene and its promoter is silenced in CRC [98]. High methylation of SST ctDNA in sera of CRC patients who only underwent elective curative surgical resection is associated with low cancer-specific survival especially in stage III and with low DFS as well as higher risk of recurrence [99]. Patients having hypermethylation levels in their serum of $A P C$ gene (encodes tumor suppressor that destabilizes and degrades $\beta$-catenin) preoperatively and TAC1 gene (encodes a neuroendocrine gastrointestinal peptide) at 6-month follow-up had unfavorable OS particularly in early stage CRC and poor DFS respectively $[81,93]$.

Panels of methylated ctDNA were examined to predict the prognosis of CRC patients. A recent study of a panel of 13 methylated DNA (FER1L4, VAV3, CHST2, DTX1, PDGFD, SMBT2, QKI, ZNF568, ANKRD13B, ZNF671, CNNM1, GRN2D, and JAM3) in plasma from 40 cases and 60 healthy controls detected recurrent/metastatic colorectal cancer especially in patients with liver or lung metastasis, with $90 \%$ sensitivity, $90 \%$ specificity, and an AUC of 0.96 [59]. A five gene prognostic methylation panel consisting of MYO1G, CALML4, GCET2, KLF3, and $A T X N 1$ genes were identified using targeted bisulfite sequencing of 801 CRC patients and 1021 healthy controls after marker selection based on comparison of CRC tissue DNA methylation data from TCGA and normal blood leukocyte methylation data from an aging study [57]. In spite of the inconsistencies in sample types of CRC and controls that might increase data deviation in marker screening, Luo et al. built a prognostic prediction model using the five genes and formulated combined prognosis score (cp-score) that takes into consideration the training and validation datasets. High cp-score in plasma of CRC patients was associated with poor prognosis and was an independent prognostic risk factor in a multivariable analysis in both training and validation cohorts. This cp-score was even superior to other prognostic risk factors (CEA status, TNM stage, and primary tumor location) [57]. Another five gene methylation panel of EYA4, GRIA4, ITGA4, MAP3K14-AS1, MSC genes was first discovered in genome-wide methylation microarrays of CRC cell lines and validated in tumor tissue and ctDNA from metastatic CRC patients [100]. Hypermethylation of this panel in the pretherapy plasma of metastatic CRC patients receiving regorafenib treatment was associated with worse OS and increased risk of progression, while its level during regorafenib treatment or its dynamic change was correlated with shorter PFS [101]. Hence its longitudinal assessment as a dynamic biomarker could be utilized relatively early during the treatment of metastatic CRC patients, before radiological assessment, to identify those with a negative prognosis.

\section{Challenges and recommendations}

Detection of circulating tumor-derived methylated DNA biomarkers in CRC might help in diagnosis, prognosis, and prediction (Fig. 1). Since methylated ctDNA is a stable molecule with high clinical sensitivity and ease in detection in a minimally invasive manner, several studies have investigated the performance of a single or a panel of such potential blood-based markers, but further essential standardization and fine-tuning are required. Some studies followed checklists to ensure complete and transparent reporting such as the REMARK (REporting recommendations for tumor MARKer prognostic studies) consisting of 20 items to report for published tumor marker prognostic studies [88], STROBE-ME (STrengthening the reporting of OBservational studies in Epidemiology-Molecular Epidemiology) including 22 items to be reported in epidemiological studies [102], STARD (STAndards for the Reporting of Diagnostic accuracy studies) initiative that lists 30 items for diagnostic accuracy studies [103, 104] and TRIPOD (Transparent reporting of a multivariable prediction model for individual prognosis or diagnosis) which is 22 checklist items deemed essential for transparent reporting of a prediction model study [105]. However, none of them go into thorough technical molecular details that are essential for identifying biomarkers (Fig. 2).

To begin with, the methodology for methylated ctDNA processing, isolation and quantification should be fully adjusted. A recent systematic review that discusses the methodological factors influencing recovery 


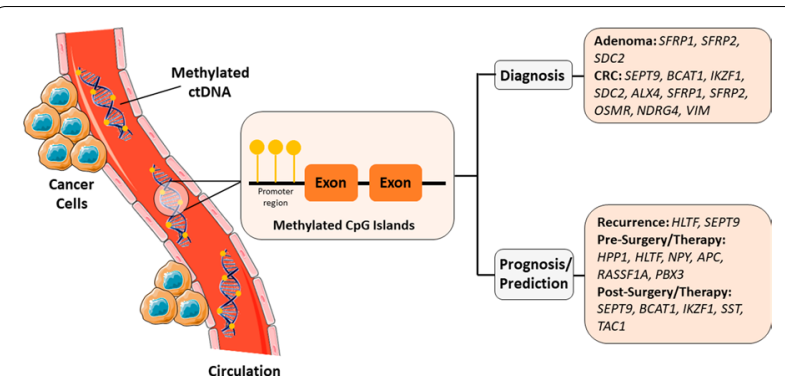

Fig. 1 Summary of potential methylated ctDNA in colorectal cancer patients as diagnostic, prognostic, and predictive circulating biomarkers. This figure was designed using some images from Servier Medical Art by Servier, licensed under a Creative Commons Attribution 3.0 Unported License (https://smart.servier.com/)

and quantification of circulating free DNA has developed recommendations for optimal conditions regarding blood specimen type, storage conditions of blood and time to processing, centrifugation speed and time, and method of ctDNA isolation and quantification [106]. The choice of plasma or serum can affect the levels of ctDNA. Higher levels of ctDNA seem to be present in serum compared to plasma due to contamination from genomic DNA which are large DNA shedding from leukocyte lysis during the clotting process. A study in 2020 using digital droplet PCR revealed that ctDNA was less frequently detected in serum of cancer patients than that in plasma where tumor-derived DNA is less diluted [107]. Processing of blood sample should be within $6 \mathrm{~h}$ and double centrifugation are needed [108]. This step is crucial to be done as quick as possible especially that methylated ctDNA is highly influenced by the proportion of cell types present in the blood sample [109]. Choosing the best method to detect DNA methylation must take into consideration: amount of DNA needed, robustness and simplicity of the method and cost. Several methods were reported in the different sections of this review. A recent review has compared four commonly used methylation methods: methylation-specific restriction endonucleases (MSRE) analysis, pyrosequencing, methylation-specific high-resolution DNA melting (MS-HRM) and quantitative methylation-specific polymerase chain reaction (qMSP) [110]. They concluded that pyrosequencing and MS-HRM are the most convenient methods. Pyrosequencing analyzes every methylated region in a chosen location, but it is a bit costly. MSHRM is a quick, cheap, very accurate and easy PCR-based method. On the other hand, MSRE is an expensive assay not suitable for intermediately methylated regions. Its analysis is based on a methylation-specific digestion of DNA that does not need DNA bisulfite conversion as the other methods. qMSP is the least accurate and time-consuming method especially that its primers are designed specifically for methylated and unmethylated alleles of a chosen region. Other enhanced methods were developed like MethyLight PCR that amplifies bisulfite-converted DNA in combination with fluorescently labeled probes that hybridize specifically to a predefined DNA methylation pattern. Combination of multiple biomarkers has been used to improve sensitivity of diagnostic tests such as ColoDefense assay which is multiplex qPCR that was used to detect the methylation of SEPT9 and $S D C 2$, from purified bisulfite-converted DNA, simultaneously [16, 17]. Recently, digital droplet PCR has been reported to

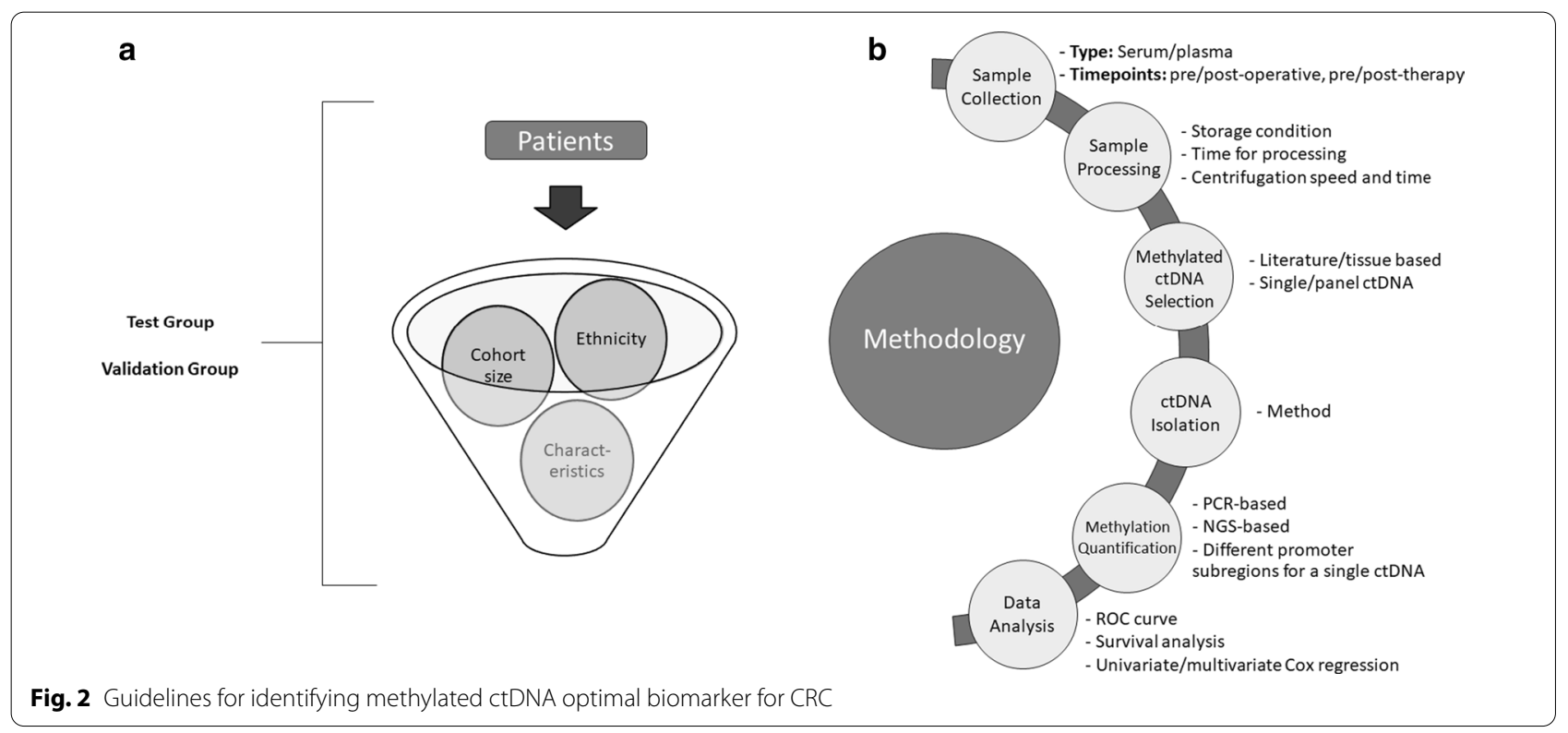


be more sensitive than real time PCR for detection of low abundant targets such as methylated ctDNA with higher precision, greater accuracy, and technical simplicity [111]. It might be a better technology to detect AA since detection of abnormal methylation in blood depends on the methylation level in abnormal tissue and the amount of DNA that can be released into circulation from cell turnover $[82,110]$. Another novel way to improve the detection rate of methylated ctDNA is to use multiple DNA methylation markers of different subregions in the promoter rather than one subregion as done by Jin et al. for SEPT9. As such, testing multiple DNA methylation markers will overcome any variations in DNA methylation patterns and make it more sensitive particularly in patients with early-stage cancer or early in recurrence [29]. Notably, this method of multiple markers was even more sensitive in postoperative and follow-up plasma samples than targeted NGS covering 532 cancer-related genes for plasma ctDNA detection.

In addition to that, most of the studies identifying blood-based methylated DNA biomarkers were examined on a small size of patients of different characteristics but on specific ethnic groups. A study has shown that the global leukocyte DNA methylation can differ by gender and race/ethnicity in peripheral blood which should be taken into consideration when choosing a biomarker [112]. For instance, most of the studies on HLTF and HPP1 methylated ctDNA were done in the same ethnic groups in Germany which should be further validated in other ethnic groups. Studies have shown that DNA methylation detected in CRC tissues could be divergent between different populations [113, 114]. For example, a study conducted on 51 Iranian and 51 African-American CRC tissues showed that the latter had higher GPNMB, ICAM5, and CHD5 promoter methylation levels than Iranians [115]. Even though these studies were done on tissues, some studies showed concordance between circulating ctDNA and tumor tissue methylation profile of specific genes. When comparing the methylation status between tissues and their matched plasma/serum, some markers showed high concordance like RUNX3 (94.4\%) and SFRP1 (94.3\%) [116] while others showed low concordance like OSMR (48\%) [42]. Moreover, SEPT9 showed a positive correlation between tumor tissues and their matched plasma with a $p$-value of 0.001 [21] and NEUROG1 showed a positive correlation between tumor tissues and their matched serum in 18 out of 35 samples [49], suggesting that some methylated ctDNA might be accessible biomarkers for CRC detection in circulation. In addition, DNA methylation pattern might be affected by the age of the studied population. As mentioned previously, a model of seven methylated gene promoter regions (ALX4, BMP3, NPTX2, RARB, SDC2, SEPT9, and
$V I M)$ and the covariates, female gender, and age greater than 66 years, had the ability to distinguish colorectal patients from healthy individuals [13]. Another study showed that CRC subjects older than 60 years had significantly higher methylation levels of SEPT9 in the plasma as compared to the younger subjects $(40.1 \%$ vs $24.2 \%)$ [25]. On the other hand, the presence of methylated NDRG4, GATA5, FOXE1, and SYNE1 in plasma was not associated with age and gender [50]. Hence, further validation studies must be performed on a larger sample size of different ethnicities, different age groups, and specific characteristics (receiving specific treatment or with specific mutations or of particular stages). Some of studies were restricted by a relatively short clinical follow-up, so further investigations with longer clinical monitoring are still required to assess the reliability of prognostic biomarkers in clinical decision-making for patients. In the studies investigating the prognosis of methylated ctDNA, defined blood sampling intervals are required to clarify the best time to determine the ctDNA status in terms of predicting. For example, direct postoperative level of methylated ctDNA may be affected by severe inflammation or stress after surgery which may lead to increased cell turnover rate and subsequently temporary increase of methylated ctDNA level [82]. Thus, longitudinal monitoring post-resection must be done for each biomarker. Since CRC recurrence and tumorigenesis, may develop through various pathways, different methylation markers become detectable at different time frames, so a combination panel of methylation markers rather than single one for monitoring is required [81].

Interestingly, for prognostic and predictive methylated ctDNA, each study investigating utilized a different method other than multivariate analysis to increase the robustness of these markers. Akaike information criterion (AIC) was used to compare different Cox models by evaluating the performance of models either combining any of the parameters or testing parameters alone [76, 79]. Small AIC indicates better models. For instance, a study compared a model including established clinical parameters alone, like the mutational status, grading, Eastern Cooperative Oncology Group performance status, and tumor load or in combination with the $\mathrm{mHPP} 1$ ctDNA and/or CEA levels in blood sample before and after therapy [79]. Another powerful statistical tool called the propensity score (PS) method was used to decrease the likelihood of confounding bias when analyzing observational data from a cohort study in order to obtain results closer to a completely randomized control study [117]. This score is more practical and statistically more efficient than other conventional strategies such as matching on covariates, stratified analyses, or multivariate statistical methods [118]. Another method that 
discriminated accurately between patients of different prognosis was combined prognostic score that multiplies the unbiased coefficient estimates (from the trained model) and the marker methylation value matrix in both the training and validation datasets [57].

\section{Conclusion}

Based on this review, methylated ctDNAs have a promising future as a circulating biomarker for CRC diagnosis, prognosis, and prediction. Therefore, these biomarkers could help us improve CRC early detection and patient care and surveillance after large-scale clinical trials and validations. This minimally invasive liquid biopsy biomarker still requires not only optimization and standardization of blood collection, ctDNA isolation, and quantification but also the evaluation of its performance as a biomarker to encourage its use in clinical practice. The performance of the biomarkers is affected by the cutoffs considered to determine the sensitivity and specificity, the statistical analyses between the biomarker and the needed outcome, the low sample size as well as the ethnic and age group of the participants. Furthermore, the development of algorithms or scores, which increase the robustness of these markers through taking into consideration the confounding factors, will be a further tool to improve the current efficacy of this biomarker. Finally, more research is needed to find the predictive role of circulating DNA methylation since little is reported on this rising potential.

\footnotetext{
Abbreviations

AA: Advanced adenoma; AIC: Akaike information criterion; ALX4: Aristaless-like homeobox 4; APC: Adenomatous polyposis coli; AUC: Area under the curve; BCAT1: Branched-chain amino acid transaminase 1; BMP3: Bone morphogenetic protein 3; CA19-9: Carbohydrate antigen; cd-score: Combined diagnostic score; CEA: Carcinoembryonic antigen; cp-score: Combined prognosis score; CRC: Colorectal cancer; CT: Computed tomography; CTC: Circulating tumor cells; ctDNA: Circulating tumor DNA; EMT: Epithelial-to-mesenchymal transition; FDA: Food and Drug Administration; FIT: Fecal immunohistochemical test; FOBT: Fecal occult blood test; GATM: Glycine amidinotransferase, mitochondrial; GEO: Gene Expression Omnibus; HLTF: Helicase-like transcription factor; HPP1: Hyperplastic polyposis 1; IKZF1: IKAROS family zinc finger 1; IRF4: Interferon regulatory factor 4; LDH: Lactate dehydrogenase; MAPK: Mitogenactivated protein kinase; MCTA-Seq: Methylated CpG tandem amplification and sequencing; mSEPT9: Methylated Septin 9; MS-HRM: Methylation-specific high-resolution DNA melting; MSRE: Methylation-specific restriction endonucleases; NAA: Non-advanced adenoma; NCI: National Cancer Institute; NPTX2: Neuronal pentraxin 2; OS: Overall survival; OSMR: Oncostatin M receptor; PCR Polymerase chain reaction; PDR: Positive detection rate; PFS: Progressionfree survival; PS: Propensity score; qMSP: Quantitative methylation-specific real-time PCR; RARB: Retinoic acid receptor beta; REMARK: REporting recommendations for tumor MARKer prognostic studies; ROC: Receiver operating characteristic; SDC2: Syndecan-2; SEER: Surveillance, Epidemiology, and End Results; SFRP1: Secreted frizzled-related protein 1; SFRP2: Secreted frizzledrelated protein 2; SSP: Sessile serrated adenomas/polyps; SST: Somatostatin; STARD: STAndards for the Reporting of Diagnostic accuracy studies; STROBEME: STrengthening the reporting of OBservational studies in EpidemiologyMolecular Epidemiology; TAC1: Tachykinin-1; TCGA: The Cancer Genome Atlas; TJP2: Tight junction protein 2; TRIPOD: Transparent reporting of a multivariable prediction model for individual prognosis or diagnosis; VIM: Vimentin.
}

\section{Acknowledgements}

We would like to thank L'Oreal -Unesco Women In Science Levant Young Talent Fellowship for their support.

\section{Authors' contributions}

FN and ZM wrote the manuscript and RN and ST designed and reviewed the manuscript. All authors read and approved the final manuscript.

\section{Funding}

Funding information is not applicable / No funding was received.

Availability of data and materials

Not applicable.

\section{Declarations}

Ethics approval and consent to participate

Not applicable.

\section{Consent for publication \\ Not applicable.}

\section{Competing interests}

The authors declare that they have no competing interests.

Received: 11 March 2021 Accepted: 2 May 2021

Published online: 17 May 2021

\section{References}

1. Bray F, Ferlay J, Soerjomataram I, Siegel RL, Torre LA, Jemal A. Global cancer statistics 2018: GLOBOCAN estimates of incidence and mortality worldwide for 36 cancers in 185 countries. CA Cancer J Clin. 2018:68:394-424.

2. Han $X$, Wang J, Sun Y. Circulating tumor DNA as biomarkers for cancer detection. Genomics Proteomics Bioinform. 2017;15(2):59-72.

3. Baassiri A, Nassar F, Mukherji D, Shamseddine A, Nasr R, Temraz S. Exosomal non coding RNA in LIQUID biopsies as a promising biomarker for colorectal cancer. Int J Mol Sci. 2020;21(4):1398.

4. Nasr R, Salim Hammoud M, Nassar F, Mukherji D, Shamseddine A, Temraz S. Inflammatory markers and microRNAs: the backstage actors influencing prognosis in colorectal cancer patients. Int J Mol Sci. 2018;19(7):1867.

5. Jahr S, Hentze H, Englisch S, Hardt D, Fackelmayer FO, Hesch RD, et al. DNA fragments in the blood plasma of cancer patients: quantitations and evidence for their origin from apoptotic and necrotic cells. Cancer Res. 2001;61(4):1659-65.

6. Mouliere F, Thierry AR. The importance of examining the proportion of circulating DNA originating from tumor, microenvironment and normal cells in colorectal cancer patients. Expert Opin Biol Therapy. 2012;12(sup1):S209-15.

7. Markowitz SD, Bertagnolli MM. Molecular origins of cancer: Molecular basis of colorectal cancer. N Engl J Med. 2009;361 (25):2449-60.

8. Vogelstein B, Papadopoulos N, Velculescu VE, Zhou S, Diaz LA Kinzler KW. Cancer genome landscapes. Science (New York, NY). 2013:339(6127):1546-58.

9. Robertson KD. DNA methylation and human disease. Nat Rev Genetics. 2005;6(8):597-610.

10. Sauerbrei W, Taube SE, MCShane LM, Cavenagh MM, Altman DG. Reporting recommendations for tumor marker prognostic studies (REMARK): an abridged explanation and elaboration. JNCI J Natl Cancer Inst. 2018;110(8):803-11.

11. Simon K. Colorectal cancer development and advances in screening. Clin Interv Aging. 2016;11:967.

12. Świderska M, Choromańska B, Dąbrowska E, Konarzewska-Duchnowska E, Choromańska K, Szczurko G, et al. The diagnostics of colorectal cancer. Contemp Oncol. 2014;18(1):1. 
13. Rasmussen SL, Krarup HB, Sunesen KG, Johansen MB, Stender MT, Pedersen IS, et al. Hypermethylated DNA, a circulating biomarker for colorectal cancer detection. PLoS ONE. 2017;12(7):e0180809.

14. Hall PA, Russell SH. The pathobiology of the septin gene family. J Pathol J Pathol Soc G B Irel. 2004;204(4):489-505.

15. Tóth K, Wasserkort R, Sipos F, Kalmár A, Wichmann B, Leiszter K, et al. Detection of methylated septin 9 in tissue and plasma of colorectal patients with neoplasia and the relationship to the amount of circulating cell-free DNA. PLOS ONE. 2014;9(12):e115415.

16. Chen Y, Wang Z, Zhao G, Sun C, Ma Y, Zhang L, et al. Performance of a novel blood-based early colorectal cancer screening assay in remaining serum after the blood biochemical test. Dis Markers. 2019:2019:5232780.

17. Zhao G, Li H, Yang Z, Wang Z, Xu M, Xiong S, et al. Multiplex methylated DNA testing in plasma with high sensitivity and specificity for colorectal cancer screening. Cancer Med. 2019;8(12):5619-28.

18. Ma ZY, Law WL, Ng EKO, Chan CSY, Lau KS, Cheng YY, et al. Methylated septin 9 and carcinoembryonic antigen for serological diagnosis and monitoring of patients with colorectal cancer after surgery. Sci Rep. 2019;9(1):10326

19. Sun J, Fei F, Zhang M, Li Y, Zhang X, Zhu S, et al. The role of (m)SEPT9 in screening, diagnosis, and recurrence monitoring of colorectal cancer. BMC Cancer. 2019;19(1):450.

20. Liu Y, Tham CK, Ong SY, Ho KS, Lim JF, Chew MH, et al. Serum methylation levels of TAC1. SEPT9 and EYA4 as diagnostic markers for early colorectal cancers: a pilot study. Biomarkers. 2013;18(5):399-405.

21. Yuan $P$, Cheng X, Wu X, Li L, Zhang L, Li Z, et al. OSMR and SEPT9: promising biomarkers for detection of colorectal cancer based on blood-based tests. Transl Cancer Res. 2016;5(2):131-9.

22. Lofton-Day C, Model F, Devos T, Tetzner R, Distler J, Schuster M, et al. DNA methylation biomarkers for blood-based colorectal cancer screening. Clin Chem. 2008;54(2):414-23.

23. Tanzer M, Balluff B, Distler J, Hale K, Leodolter A, Rocken C, et al. Performance of epigenetic markers SEPT9 and ALX4 in plasma for detection of colorectal precancerous lesions. PLoS ONE. 2010;5(2):e9061.

24. Fu B, Yan P, Zhang S, Lu Y, Pan L, Tang W, et al. Cell-free circulating methylated SEPT9 for noninvasive diagnosis and monitoring of colorectal cancer. Dis Markers. 2018;2018:6437104.

25. Xie L, Jiang X, Li Q, Sun Z, Quan W, Duan Y, et al. Diagnostic value of methylated Septin9 for colorectal cancer detection. Front Oncol. 2018:8:247

26. Chen $\mathrm{CH}$, Yan SL, Yang $\mathrm{TH}$, Chen SF, Yeh YH, Ou JJ, et al. The relationship between the methylated septin-9 DNA blood test and stool occult blood test for diagnosing colorectal cancer in Taiwanese people. J Clin Lab Anal. 2017;31(1):e22013.

27. Song $L$, Peng X, Li Y, Xiao W, Jia J, Dong C, et al. The SEPT9 gene methylation assay is capable of detecting colorectal adenoma in opportunistic screening. Epigenomics. 2017;9(5):599-610.

28. Song L, Wang J, Wang $H$, Chen Y, Jia J, Guo S, et al. The quantitative profiling of blood mSEPT9 determines the detection performance on colorectal tumors. Epigenomics. 2018;10(12):1569-83.

29. Jin S, Zhu D, Shao F, Chen S, Guo Y, Li K, et al. Efficient detection and post-surgical monitoring of colon cancer with a multi-marker DNA methylation liquid biopsy. Proc Natl Acad Sci. 2021;118(5):e2017421118.

30. Javierre BM, Rodriguez-Ubreva J, Al-Shahrour F, Corominas M, Graña $\mathrm{O}$, Ciudad L, et al. Long-range epigenetic silencing associates with deregulation of ikaros targets in colorectal cancer cells. Mol Cancer Res. 2011;9(8):1139.

31. Jedi M, Young GP, Pedersen SK, Symonds EL. Methylation and gene expression of BCAT1 and IKZF1 in colorectal cancer tissues. Clin Med Insights Oncol. 2018;12:1179554918775064.

32. Pedersen SK, Baker RT, McEvoy A, Murray DH, Thomas M, Molloy PL, et al. A two-gene blood test for methylated DNA sensitive for colorectal cancer. PLoS ONE. 2015;10(4):e0125041.

33. Young GP, Symonds EL, Nielsen HJ, Ferm L, Christensen IJ, Dekker E, et al. Evaluation of a panel of tumor-specific differentially-methylated DNA regions in IRF4, IKZF1 and BCAT1 for blood-based detection of colorectal cancer. Clin Epigenetics. 2021;13(1):14.

34. Pedersen SK, Symonds EL, Baker RT, Murray DH, McEvoy A, Van Doorn SC, et al. Evaluation of an assay for methylated BCAT1 and
IKZF1 in plasma for detection of colorectal neoplasia. BMC Cancer. 2015;15(1):654.

35. Hua R, Yu J, Yan X, Ni Q, Zhi X, Li X, et al. Syndecan-2 in colorectal cancer plays oncogenic role via epithelial-mesenchymal transition and MAPK pathway. Biomed Pharmacother. 2020;121:109630.

36. Oh T, Kim N, Moon Y, Kim MS, Hoehn BD, Park CH, et al. Genomewide identification and validation of a novel methylation biomarker, SDC2, for blood-based detection of colorectal cancer. J Mol Diagn. 2013;15(4):498-507.

37. Ebert MP, Model F, Mooney S, Hale K, Lograsso J, Tonnes-Priddy L, et al. Aristaless-like homeobox-4 gene methylation is a potential marker for colorectal adenocarcinomas. Gastroenterology. 2006;131(5):1418-30.

38. Bartak BK, Kalmar A, Peterfia B, Patai AV, Galamb O, Valcz G, et al. Colorectal adenoma and cancer detection based on altered methylation pattern of SFRP1, SFRP2, SDC2, and PRIMA1 in plasma samples. Epigenetics. 2017;12(9):751-63.

39. Li H, Wang Z, Zhao G, Ma Y, Chen Y, Xue Q, et al. Performance of a MethyLight assay for methylated SFRP2 DNA detection in colorectal cancer tissue and serum. Int J Biol Markers. 2019;34(1):54-9.

40. Kim MS, Louwagie J, Carvalho B, Sive Droste JST, Park HL, Chae YK, et al. Promoter DNA methylation of Oncostatin M receptor- $\beta$ as a novel diagnostic and therapeutic marker in colon cancer. PLoS ONE. 2009;4(8):e6555.

41. Wang Z, Li R, He Y, Huang S. Effects of secreted frizzled-related protein 1 on proliferation, migration, invasion, and apoptosis of colorectal cancer cells. Cancer Cell Int. 2018;18(1):1-10.

42. Bedin C, Enzo MV, Del Bianco P, Pucciarelli S, Nitti D, Agostini M. Diagnostic and prognostic role of cell-free DNA testing for colorectal cancer patients. Int J Cancer. 2017;140(8):1888-98.

43. Li M, Chen WD, Papadopoulos N, Goodman SN, Bjerregaard NC, Laurberg S, et al. Sensitive digital quantification of DNA methylation in clinical samples. Nat Biotechnol. 2009;27(9):858-63.

44. Lam K, Pan K, Linnekamp JF, Medema JP, Kandimalla R. DNA methylation based biomarkers in colorectal cancer: a systematic review. Biochim Biophys Acta. 2016;1866(1):106-20.

45. Picardo F, Romanelli A, Muinelo-Romay L, Mazza T, Fusilli C, Parrella $P$, et al. Diagnostic and prognostic value of B4GALT1 hypermethylation and its clinical significance as a novel circulating cell-free DNA biomarker in colorectal cancer. Cancers (Basel). 2019;11(10):1598.

46. Lee BB, Lee EJ, Jung EH, Chun HK, Chang DK, Song SY, et al. Aberrant methylation of APC, MGMT, RASSF2A, and Wif-1 genes in plasma as a biomarker for early detection of colorectal cancer. Clin Cancer Res. 2009;15(19):6185-91.

47. Zhou D, Tang W, Zhang Y, An HX. JAM3 functions as a novel tumor suppressor and is inactivated by DNA methylation in colorectal cancer. Cancer Manag Res. 2019;11:2457-70.

48. Zhou D, Tang W, Su G, Cai M, An HX, Zhang Y. PCDH18 is frequently inactivated by promoter methylation in colorectal cancer. Sci Rep. 2017;7(1):2819.

49. Herbst A, Rahmig K, Stieber P, Philipp A, Jung A, Ofner A, et al. Methylation of NEUROG1 in serum is a sensitive marker for the detection of early colorectal cancer. Am J Gastroenterol. 2011;106(6):1110-8.

50. Melotte V, Yi JM, Lentjes MH, Smits KM, Van Neste L, Niessen HE, et al. Spectrin repeat containing nuclear envelope 1 and forkhead box protein $\mathrm{E} 1$ are promising markers for the detection of colorectal cancer in blood. Cancer Prev Res (Phila). 2015;8(2):157-64.

51. Lange CP, Campan M, Hinoue T, Schmitz RF, van der Meulen-de Jong $A E$, Slingerland $H$, et al. Genome-scale discovery of DNA-methylation biomarkers for blood-based detection of colorectal cancer. PLOS ONE. 2012;7(11):e50266.

52. Melson J, Li Y, Cassinotti E, Melnikov A, Boni L, Ai J, et al. Commonality and differences of methylation signatures in the plasma of patients with pancreatic cancer and colorectal cancer. Int J Cancer. 2014;134(11):2656-62.

53. Nagai Y, Sunami E, Yamamoto Y, Hata K, Okada S, Murono K, et al. LINE-1 hypomethylation status of circulating cell-free DNA in plasma as a biomarker for colorectal cancer. Oncotarget. 2017;8(7):11906.

54. Saluja H, Young GP, Kholmurodova F, Symonds EL. Variables associated with detection of methylated BCAT1 or IKZF1 in blood from patients without colonoscopically-evident colorectal cancer. Cancer epidemiology, biomarkers and prevention: a publication of the American 
Association for Cancer Research, cosponsored by the American Society of Preventive Oncology. 2021.

55. Cock C, Anwar S, Byrne SE, Meng R, Pedersen S, Fraser RJL, et al. Low sensitivity of fecal immunochemical tests and blood-based markers of DNA hypermethylation for detection of sessile serrated adenomas/ polyps. Dig Dis Sci. 2019;64(9):2555-62.

56. Li J, Zhou X, Liu X, Ren J, Wang J, Wang W, et al. Detection of colorectal cancer in circulating cell-free DNA by methylated CpG tandem amplification and sequencing. Clin Chem. 2019;65(7):916-26.

57. Luo H, Zhao Q, Wei W, Zheng L, Yi S, Li G, et al. Circulating tumor DNA methylation profiles enable early diagnosis, prognosis prediction, and screening for colorectal cancer. Sci Transl Med. 2020;12(524):eaax7533.

58. Sui J, Wu X, Wang C, Wang G, Li C, Zhao J, et al. Discovery and validation of methylation signatures in blood-based circulating tumor cell-free DNA in early detection of colorectal carcinoma: a case-control study. Clin Epigenetics. 2021;13(1):26.

59. Xie H, Mahoney DW, Foote PH, Burger KN, Doering KA, Taylor WR, et al. Novel methylated DNA markers in the surveillance of colorectal cancer recurrence. Clin Cancer Res. 2021;27(1):141-9.

60. Roperch J-P, Incitti R, Forbin S, Bard F, Mansour H, Mesli F, et al. Aberrant methylation of NPY, PENK, and WIF1 as a promising marker for bloodbased diagnosis of colorectal cancer. BMC Cancer. 2013;13(1):566.

61. Cho NY, Park JW, Wen X, Shin YJ, Kang JK, Song SH, et al. Blood-based detection of colorectal cancer using cancer-specific DNA methylation markers. Diagnostics (Basel). 2020;11(1):51.

62. Bach S, Sluiter NR, Beagan JJ, Mekke JM, Ket JCF, van Grieken NCT, et al. Circulating tumor DNA analysis: clinical implications for colorectal cancer patients. A systematic review. JNCI Cancer Spectr. 2019;3(3):pkz042.

63. LiY, LiW. BRAF mutation is associated with poor clinicopathological outcomes in colorectal cancer: a meta-analysis. Saudi J Gastroenterol Off J Saudi Gastroenterol Assoc. 2017;23(3):144-9.

64. Guastadisegni C, Colafranceschi M, Ottini L, Dogliotti E. Microsatellite instability as a marker of prognosis and response to therapy: a meta-analysis of colorectal cancer survival data. Eur J Cancer (Oxford, England: 1990). 2010:46(15):2788-98.

65. Voorneveld PW, Jacobs RJ, Kodach LL, Hardwick JC. A meta-analysis of SMAD4 immunohistochemistry as a prognostic marker in colorectal cancer. Transl Oncol. 2015;8(1):18-24.

66. Chen TH, Chang SW, Huang CC, Wang KL, Yeh KT, Liu CN, et al. The prognostic significance of APC gene mutation and miR-21 expression in advanced-stage colorectal cancer. Colorectal Dis Off J Assoc Coloproctol G B Irel. 2013;15(11):1367-74.

67. Xu JM, Liu XJ, Ge FJ, Lin L, Wang Y, Sharma MR, et al. KRAS mutations in tumor tissue and plasma by different assays predict survival of patients with metastatic colorectal cancer. J Exp Clin Cancer Res CR. 2014:33(1):104

68. Wang JY, Hsieh JS, Chang MY, Huang TJ, Chen FM, Cheng TL, et al. Molecular detection of APC, K- ras, and p53 mutations in the serum of colorectal cancer patients as circulating biomarkers. World I Surg. 2004;28(7):721-6.

69. Li MX, Liu XM, Zhang XF, Zhang JF, Wang WL, Zhu Y, et al. Prognostic role of neutrophil-to-lymphocyte ratio in colorectal cancer: a systematic review and meta-analysis. Int J Cancer. 2014;134(10):2403-13.

70. Tsai PL, Su WJ, Leung WH, Lai CT, Liu CK. Neutrophil-lymphocyte ratio and CEA level as prognostic and predictive factors in colorectal cancer: a systematic review and meta-analysis. J Cancer Res Therap. 2016;12(2):582-9.

71. Locker GY, Hamilton S, Harris J, Jessup JM, Kemeny N, Macdonald JS, et al. ASCO 2006 update of recommendations for the use of tumor markers in gastrointestinal cancer. J Clin Oncol Off J Am Soc Clin Oncol. 2006;24(33):5313-27.

72. Renehan AG, Egger M, Saunders MP, O'Dwyer ST. Impact on survival of intensive follow up after curative resection for colorectal cancer: systematic review and meta-analysis of randomised trials. BMJ (Clin Res Ed). 2002;324(7341):813.

73. Hauptman N, Glavač D. Colorectal cancer blood-based biomarkers. Gastroenterol Res Pract. 2017;2017:2195361.

74. Young J, Biden KG, Simms LA, Huggard P, Karamatic R, Eyre HJ, et al. HPP1: a transmembrane protein-encoding gene commonly methylated in colorectal polyps and cancers. Proc Natl Acad Sci. 2001;98(1):265-70.
75. Moinova HR, Chen WD, Shen L, Smiraglia D, Olechnowicz J, Ravi L, et al. HLTF gene silencing in human colon cancer. Proc Natl Acad Sci USA. 2002;99(7):4562-7.

76. Philipp AB, Stieber P, Nagel D, Neumann J, Spelsberg F, Jung A, et al. Prognostic role of methylated free circulating DNA in colorectal cancer. Int J Cancer. 2012;131(10):2308-19.

77. Wallner M, Herbst A, Behrens A, Crispin A, Stieber P, Goke B, et al. Methylation of serum DNA is an independent prognostic marker in colorectal cancer. Clin Cancer Res. 2006;12(24):7347-52.

78. Philipp AB, Nagel D, Stieber P, Lamerz R, Thalhammer I, Herbst A, et al. Circulating cell-free methylated DNA and lactate dehydrogenase release in colorectal cancer. BMC Cancer. 2014;14:245.

79. Herbst A, Vdovin N, Gacesa S, Philipp A, Nagel D, Holdt LM, et al. Methylated free-circulating HPP1 DNA is an early response marker in patients with metastatic colorectal cancer. Int J Cancer. 2017;140(9):2134-44.

80. Herbst A, Wallner M, Rahmig K, Stieber P, Crispin A, Lamerz R, et al. Methylation of helicase-like transcription factor in serum of patients with colorectal cancer is an independent predictor of disease recurrence. Eur J Gastroenterol Hepatol. 2009;21 (5):565-9.

81. Tham C, Chew M, Soong R, Lim J, Ang M, Tang C, et al. Postoperative serum methylation levels ofTAC1 andSEPT9are independent predictors of recurrence and survival of patients with colorectal cancer. Cancer. 2014;120(20):3131-41.

82. Song L, Guo S, Wang J, Peng X, Jia J, Gong Y, et al. The blood mSEPT9 is capable of assessing the surgical therapeutic effect and the prognosis of colorectal cancer. Biomark Med. 2018;12(9):961-73.

83. Yang X, Xu ZJ, Chen X, Zeng SS, Qian L, Wei J, et al. Clinical value of preoperative methylated septin 9 in Chinese colorectal cancer patients. World J Gastroenterol. 2019;25(17):2099-109,

84. Mitchell SM, Ross JP, Drew HR, Ho T, Brown GS, Saunders NF, et al. A panel of genes methylated with high frequency in colorectal cancer. BMC Cancer. 2014;14:54

85. Ogasawara M, Murata J, Ayukawa K, Saiki I. Differential effect of intestinal neuropeptides on invasion and migration of colon carcinoma cells in vitro. Cancer Lett. 1997;1 19(1):125-30.

86. Jensen LH, Olesen R, Petersen LN, Boysen AK, Andersen RF, Lindebjerg J, et al. NPY gene methylation as a universal, longitudinal plasma marker for evaluating the clinical benefit from last-line treatment with regorafenib in metastatic colorectal cancer. Cancers. 2019;1 1(11):1649.

87. Garrigou S, Perkins G, Garlan F, Normand C, Didelot A, Le Corre D, et al. A study of hypermethylated circulating tumor DNA as a universal colorectal cancer biomarker. Clin Chem. 2016;62(8):1129-39.

88. Appelt AL, Andersen RF, Lindebjerg J, Jakobsen A. Prognostic value of serum NPY hypermethylation in neoadjuvant chemoradiotherapy for rectal cancer: secondary analysis of a randomized trial. Am J Clin Oncol. 2020;43(1):9-13.

89. Thomsen CB, Hansen TF, Andersen RF, Lindebjerg J, Jensen LH, Jakobsen A. Early identification of treatment benefit by methylated circulating tumor DNA in metastatic colorectal cancer. Therap Adv Med Oncol. 2020;12:1758835920918472.

90. Cao D, Chen Y, Tang Y, Peng X-C, Dong H, Li L-H, et al. Loss of RASSF1A expression in colorectal cancer and its association with K-ras status. BioMed Res Int. 2013;2013:976765.

91. Sakamoto N, Terai T, Ajioka Y, Abe S, Kobayasi O, Hirai S, et al. Frequent hypermethylation of RASSF1A in early flat-type colorectal tumors. Oncogene. 2004;23(55):8900-7.

92. Sun X, Yuan W, Hao F, Zhuang W. Promoter Methylation of RASSF1A indicates prognosis for patients with stage II and III colorectal cancer treated with oxaliplatin-based chemotherapy. Med Sci Monit Int Med J Exp Clin Res. 2017;23:5389-95.

93. Matthaios D, Balgkouranidou I, Karayiannakis A, Bolanaki H, Xenidis $\mathrm{N}$, Amarantidis $\mathrm{K}$, et al. Methylation status of the APC and RASSF1A promoter in cell-free circulating DNA and its prognostic role in patients with colorectal cancer. Oncol Lett. 2016;12(1):748-56.

94. Murray DH, Symonds EL, Young GP, Byrne S, Rabbitt P, Roy A, et al. Relationship between post-surgery detection of methylated circulating tumor DNA with risk of residual disease and recurrence-free survival. J Cancer Res Clin Oncol. 2018;144(9):1741-50.

95. Young GP, Pedersen SK, Mansfield S, Murray DH, Baker RT, Rabbitt P, et al. A cross-sectional study comparing a blood test for methylated 
BCAT1 and IKZF1 tumor-derived DNA with CEA for detection of recurrent colorectal cancer. Cancer Med. 2016;5(10):2763-72.

96. Symonds EL, Pedersen SK, Murray D, Byrne SE, Roy A, Karapetis C, et al. Circulating epigenetic biomarkers for detection of recurrent colorectal cancer. Cancer. 2020;126(7):1460-9.

97. Musher BL, Melson JE, Amato G, Chan D, Hill M, Khan I, et al. Evaluation of circulating tumor DNA for methylated BCAT1 and IKZF1 to detect recurrence of stage II/stage III colorectal cancer (CRC). Cancer Epidemiol Biomark Prev. 2020;29(12):2702-9.

98. Leiszter K, Sipos F, Galamb O, Krenács T, Veres G, Wichmann B, et al. Promoter hypermethylation-related reduced somatostatin production promotes uncontrolled cell proliferation in colorectal cancer. PLOS ONE. 2015;10(2):e0118332.

99. Liu Y, Chew MH, Tham CK, Tang CL, Ong SY, Zhao Y. Methylation of serum SST gene is an independent prognostic marker in colorectal cancer. Am J Cancer Res. 2016;6(9):2098-108.

100. Barault L, Amatu A, Siravegna G, Ponzetti A, Moran S, Cassingena A, et al. Discovery of methylated circulating DNA biomarkers for comprehensive non-invasive monitoring of treatment response in metastatic colorectal cancer. Gut. 2018;67(11):1995-2005.

101. Amatu A, Schirripa M, Tosi F, Lonardi S, Bencardino K, Bonazzina E, et al. High circulating methylated DNA is a negative predictive and prognostic marker in metastatic colorectal cancer patients treated with regorafenib. Front Oncol. 2019;9:622.

102. Gallo V, Egger M, McCormack V, Farmer PB, loannidis JPA, Kirsch-Volders $\mathrm{M}$, et al. STrengthening the reporting of OBservational studies in Epidemiology —Molecular Epidemiology (STROBE-ME): an extension of the STROBE statement. Eur J Epidemiol. 2011;26(10):797-810.

103. Cohen JF, Korevaar DA, Altman DG, Bruns DE, Gatsonis CA, Hooft L, et al. STARD 2015 guidelines for reporting diagnostic accuracy studies: explanation and elaboration. BMJ Open. 2016;6(11):e012799.

104. Bossuyt PM, Reitsma JB, Bruns DE, Gatsonis CA, Glasziou PP, Irwig LM, et al. Toward complete and accurate reporting of studies of diagnostic accuracy: the STARD initiative. Acad Radiol. 2003;10(6):664-9.

105. Collins GS, Reitsma JB, Altman DG, Moons KG. Transparent reporting of a multivariable prediction model for individual prognosis or diagnosis (TRIPOD): the TRIPOD statement. BMJ (Clin Res Ed). 2015;350:g7594.

106. Trigg RM, Martinson LJ, Parpart-Li S, Shaw JA. Factors that influence quality and yield of circulating-free DNA: a systematic review of the methodology literature. Heliyon. 2018;4(7):e00699.
107. Lee JS, Kim M, Seong MW, Kim HS, Lee YK, Kang HJ. Plasma vs. serum in circulating tumor DNA measurement: characterization by DNA fragment sizing and digital droplet polymerase chain reaction. Clin Chem Lab Med. 2020;58(4):527-32.

108. Chan KA, Yeung S-W, Lui W-B, Rainer TH, Lo YD. Effects of preanalytical factors on the molecular size of cell-free DNA in blood. Clin Chem. 2005;51(4):781-4.

109. Johansson G, Andersson D, Filges S, Li J, Muth A, Godfrey TE, et al. Considerations and quality controls when analyzing cell-free tumor DNA. Biomol Detect Quantif. 2019;17:100078.

110. Šestáková Š, Šálek C, Remešová H. DNA methylation validation methods: a coherent review with practical comparison. Biol Proced Online. 2019;21(1):19.

111. Taylor SC, Laperriere G, Germain H. Droplet Digital PCR versus qPCR for gene expression analysis with low abundant targets: from variable nonsense to publication quality data. Sci Rep. 2017;7(1):2409.

112. Zhang FF, Cardarelli R, Carroll J, Fulda KG, Kaur M, Gonzalez K, et al. Significant differences in global genomic DNA methylation by gender and race/ethnicity in peripheral blood. Epigenetics. 2011;6(5):623-9.

113. Fraser HB, Lam LL, Neumann SM, Kobor MS. Population-specificity of human DNA methylation. Genome Biol. 2012;13(2):R8.

114. Xia YY, Ding YB, Liu XQ, Chen XM, Cheng SQ, Li LB, et al. Racial/ethnic disparities in human DNA methylation. Biochim Biophys Acta. 2014;1846(1):258-62.

115. Mokarram P, Kumar K, Brim H, Naghibalhossaini F, Saberi-firoozi M, Nouraie M, et al. Distinct high-profile methylated genes in colorectal cancer. PLOS ONE. 2009;4(9):e7012.

116. Pasha HF, Radwan MI, Yehia AM, Toam MM. Circulating methylated RUNX3 and SFRP1 genes as a noninvasive panel for early detection of colorectal cancer. Eur J Gastroenterol Hepatol. 2019;31(11):1342-9.

117. Sun $H$, Huang $H$, Li D, Zhang L, Zhang Y, Xu J, et al. PBX3 hypermethylation in peripheral blood leukocytes predicts better prognosis in colorectal cancer: a propensity score analysis. Cancer Med. 2019;8(8):4001-11.

118. Haukoos JS, Lewis RJ. The propensity score. JAMA. 2015;314(15):1637-8.

\section{Publisher's Note}

Springer Nature remains neutral with regard to jurisdictional claims in published maps and institutional affiliations.
Ready to submit your research? Choose BMC and benefit from:

- fast, convenient online submission

- thorough peer review by experienced researchers in your field

- rapid publication on acceptance

- support for research data, including large and complex data types

- gold Open Access which fosters wider collaboration and increased citations

- maximum visibility for your research: over $100 \mathrm{M}$ website views per year

At BMC, research is always in progress.

Learn more biomedcentral.com/submissions 